\title{
Thermal Analysis of Heat Distribution in Busbars during Rated Current Flow in Low-Voltage Industrial Switchgear
}

\author{
Michał Szulborski *D, Sebastian Łapczyński and Łukasz Kolimas (D) \\ Faculty of Electrical Engineering, Electrical Power Engineering Institute, Warsaw University of Technology, \\ 00-662 Warsaw, Poland; seb.lapczynski@gmail.com (S.Ł.); lukasz.kolimas@ien.pw.edu.pl (Ł.K.) \\ * Correspondence: mm.szulborski@gmail.com; Tel.: +48-662-119-014
}

Citation: Szulborski, M.; Łapczyński, S.; Kolimas, Ł. Thermal Analysis of Heat Distribution in Busbars during Rated Current Flow in Low-Voltage Industrial Switchgear. Energies 2021, 14, 2427.

https://doi.org/10.3390/en14092427

Academic Editor: Fabio Polonara

Received: 1 March 2021

Accepted: 22 April 2021

Published: 24 April 2021

Publisher's Note: MDPI stays neutral with regard to jurisdictional claims in published maps and institutional affiliations.

Copyright: (c) 2021 by the authors. Licensee MDPI, Basel, Switzerland. This article is an open access article distributed under the terms and conditions of the Creative Commons Attribution (CC BY) license (https:// creativecommons.org/licenses/by/ $4.0 /)$.

\begin{abstract}
The manuscript presents advanced coupled analysis: Maxwell 3D, Transient Thermal and Fluent CFD, at the time of a rated current occurring on the main busbars in the low-voltage switchgear. The simulations were procured in order to aid the design process of such enclosures. The analysis presented the rated current flow in the switchgear busbars, which allowed determining their temperature values. The main assumption of the simulation was measurements of temperature rise during rated current conditions. Simulating such conditions is a valuable asset in order to design better solutions for energy distribution gear. The simulation model was a precise representation of the actual prototype of the switchgear. Simulations results were validated by experimental research. The heat dissipation in busbars and switchgear housing through air convection was presented. The temperature distribution for the insulators in the rail bridge made of fireproof material was considered: halogen-free polyester. The results obtained during the simulation allowed for a detailed analysis of switchgear design and proper conclusions in practical and theoretical aspects. That helped in introducing structural changes in the prepared prototype of the switchgear at the design and construction stages. Deep analysis of the simulation results allowed for the development concerning the final prototype of the switchgear, which could be subjected to the full type tests. Additionally, short-circuit current simulations were procured and presented.
\end{abstract}

Keywords: heat distribution; thermal analysis; electromagnetic analysis; conduction; convection; radiation; CFD simulation; ANSYS coupled analysis; low-voltage switchgear; FEM simulations

\section{Introduction}

Industrial low-voltage switchgears are electrical devices that allow power distribution. It is necessary to properly protect, control, and monitor the discharge lines from the switchgear to the energy receivers [1]. Low-voltage switchgears are manufactured based on the requirements specified in the IEC 61439 standard (low-voltage switchgear and controlgear assemblies). Therefore, they must meet all requirements for electrical, mechanical, and thermal parameters [2].

In order to meet the thermal requirements for the switchgear, the ratio of heat generated by the active elements in the switchgear must be smaller than the heat dissipation capacity of the entire layout (passive system). Heat transfer to the environment, in this case, is performed by convection, conduction, and radiation [3].

Skin effect, contact resistance, proximity effect occurring in the current circuits, and the resistivity of the material from which the current circuits are made (e.g., busbars) contribute significantly to the generation of increased heat [4-6]. After taking them into account, it is possible to determine active power losses according to Joule's law expressed in watts [7]. Thermal calculations of the current circuits are carried out by heating the busbars with operating currents of a continuous nature and heating from the short-circuit currents [8].

For both situations, the criterion of the permissible thermal condition of the circuit should not exceed the permissible temperature values. Those are standardized and depend 
on the properties of the circuit material and the environment in the immediate vicinity of the current circuit [9]. Properties were determined considering factors such as reduction of mechanical strength, loss of plasticity, and accelerated aging processes. Under short-circuit conditions, the permissible circuit temperature is higher due to the short-circuit current flow time.

The long-term power load of the busbars with the rated current in the switchgear is defined as the maximum power load of the busbars with the current, which effect does not exceed the temperature for the current circuit [10]. An important parameter describing this phenomenon is the time constant $(\mathrm{T})$ of the current circuit heating. The calculation of the time value of the current circuit heating time (T) allows determining, with high accuracy, the time of heating to the set temperature [11]. After determining one time constant, the temperature increase reaches the value of 0.632 of the temperature in the steady-state of the current circuit. After calculating the five time constants $(\mathrm{T})$, the calculated temperature rise reaches 0.98 of the permissible temperature in the steady-state of the current circuit. Heat transfer of the heated busbars in the switchgear can take place in three ways: by conductivity, convection, and radiation. In the calculation scenarios of electrical equipment current circuits, all or only some of these types of heating may occur [12-14].

The phenomenon of convection relates to the exchange of thermal energy between a solid and a gas or liquid in the immediate vicinity of the solid. It is related to the movement of gas or liquid and depends mainly on the physical properties of the media, the shape and dimensions of the solid surface, temperature difference, and the method of excitation [15]. An analytical determination of the amount of thermal energy transferred by convection is a difficult issue due to the large number of variables and the complexity of initial and boundary conditions.

Radiation is the process of transferring energy from the radiating body to other bodies in the vicinity. The radiating body is characterized by the emission of electromagnetic waves consisting of various wavelengths [16]. The wavelength range with the highest thermal energy transfer is from 0.4 to $10 \mu \mathrm{m}$. These can be observed in the infrared region, which is invisible to the human eye. The contribution of radiation to heat transfer and to the environment is primarily dependent on the temperature difference and emissivity between the radiating body and the environment [17]. With a small difference in the order of magnitude, a few or several degrees, radiation plays a small role. Heat is transferred practically by convection. With a temperature difference of several dozen degrees, the proportion of radiation increases significantly and amounts to about $50 \%$. This is the temperature range that occurs in the design of current circuits, so the effect of radiating heat should be considered. Radiation is treated as the release of heat along straight lines perpendicular to the surface of the emitting body [18]. The degree of blackness $(\varepsilon)$ of the body radiating heat also affects the radiation efficiency. Covering current circuits (especially with copper and aluminum) with various types of layers and varnishes helps increase the radiated heat flux. This is a widely recognized and affordable activity. This increases the current carrying capacity while maintaining the original heating temperature. In most cases, heat losses through radiation and convection determine the load capacity of the busbar system [19]. The share of heat losses by lifting and radiation depends on the geometrical dimensions of the rail system. In general, the proportion of convection decreases for smaller conductors, while it increases for larger structures [20].

During laboratory tests, specific points in the switchgear are examined where an increase in temperature is expected [21]. However, this does not fully reflect the entire temperature range witnessed in the current circuits present inside the switchgear [22]. In addition, performing these types of tests is a complicated operation, expensive and time-consuming. It requires several tests before developing the finished product. In order to reduce the costs of this type of research [23-27], it is possible to prepare a detailed 3D model of the switchgear and perform a computer simulation in the ANSYS Workbench environment. In addition, using coupled analyses: Maxwell 3D, Fluent CFD, Transient Thermal, allowing for an accurate temperature distribution on the busbars and inside 
the switchgear [28-31]. This type of calculation allows the structure to be optimized in terms of high temperature resistance, as well as heat dissipation from the switchgear to the environment [32-37]. The novelty of the approach is clearly the cost reduction concerning expensive experimental research and also the ability to reduce materials quantities that ought to be used for switchgear assembly.

The purpose of this work is to analyze the temperature distribution in busbars during rated current flow. A simulation model of physical-thermal phenomena occurring during the flow of current through current circuits in low-voltage switchgear was developed in work and experimentally validated. Additionally, the short-circuit currents simulations and analysis were added but not validated because of the humongous costs that those approaches would take.

The subject of theoretical analysis and simulation were the busbars of low-voltage switchgears and the associated contacts. The presented theoretical test results can be used by designers and manufacturers of switchgears, busbars, and low-voltage electrical apparatus. The paper examines in particular issues regarding:

- Load distribution in current paths;

- Temperature distribution in busbars.

These issues are analyzed in the case of selected systems, requirements, and adopted assessment criteria regarding values:

- Permanent load transfer;

- Failure elimination;

- The arrangement of current circuits and the devices supplied by them.

These criteria are the basis for assessing the proposed design solutions for current circuit systems and their selection in low-voltage switchgears. Taking into account these criteria, appropriate mathematical models have been created that are the basis for all analyzes and simulations of current circuits, their connections in low-voltage switchgears, as well as the implementation of these solutions for production.

In the current conditions of free competition, producers who want to stay on the market are forced to constantly reduce the duration of the launch of a new product, lower its price, increase its utility values, quickly respond to changing customer requirements and adapt to a constantly changing environment. The most effective way to cope with such pressure is to use various types of computer-aided engineering techniques related to it.

An indispensable theoretical base enabling the correct approach to the problem is the book concerning electrical contacts by P. Slade [26], which contains theoretical and practical information about physical phenomena occurring in current circuit contacts. In particular, issues related to the calculation of contact resistance and contact welding were discussed, and the problem of selecting contact materials was presented. Other publications used by Milenko Braunovic are publications $[9,10]$. The authors showed how important mechanical and electrical characteristics affect the overall reliability and performance of a current circuit contact system.

To date, many scientists have been involved in the analysis and research of busbars. Particular mention should be made of the works of A. Plesca, studies $[1,8]$, in which thermal analyzes in busbars were presented and discussed. In both articles, the author presents simulations of current flow in current paths consistent with the results of experimental research.

The publication J. Lotiya [6] is valuable in the area of heating up high-current flat busbars. The author discusses screw connections of flat busbars commonly used in electrical systems of power stations. The paper presents the analysis of the influence of the clamping force of the screw connection on the value of temperatures achieved in contact with the flow of interference currents on the example of flat copper bars. The issue of heating the current circuits in switchgears is complemented by publications by M. Bedkowski and co-authors [3,18], in which the authors presented a simulation thermal analysis of current circuits for rated currents of prototype switchgears using a CFD solver. 
Valuable publications are the works of D. Chapman and T. Norris [4] and R. Berrett [5], which accurately describe how calculations related to flow and heat dissipation from current circuits by convection and radiation should be performed, the authors thoroughly discuss in their works what should mathematical models look like for this type of thermal calculations.

Other works on the generation and dissipation of heat from current circuits during the current flow allowed for a precise reference to the problem in the presented publication $[2,6,7,14-16]$.

\section{The Mathematical Model}

Thermal energy in the switchgear is generated by the rated current, or short-circuit current flowing through the main current busbars and wires leaving the switchgear. The thermal energy from the current busbars is dissipated to the environment by convection, conduction, and radiation. The relationships describing these phenomena are presented below in Figure 1.

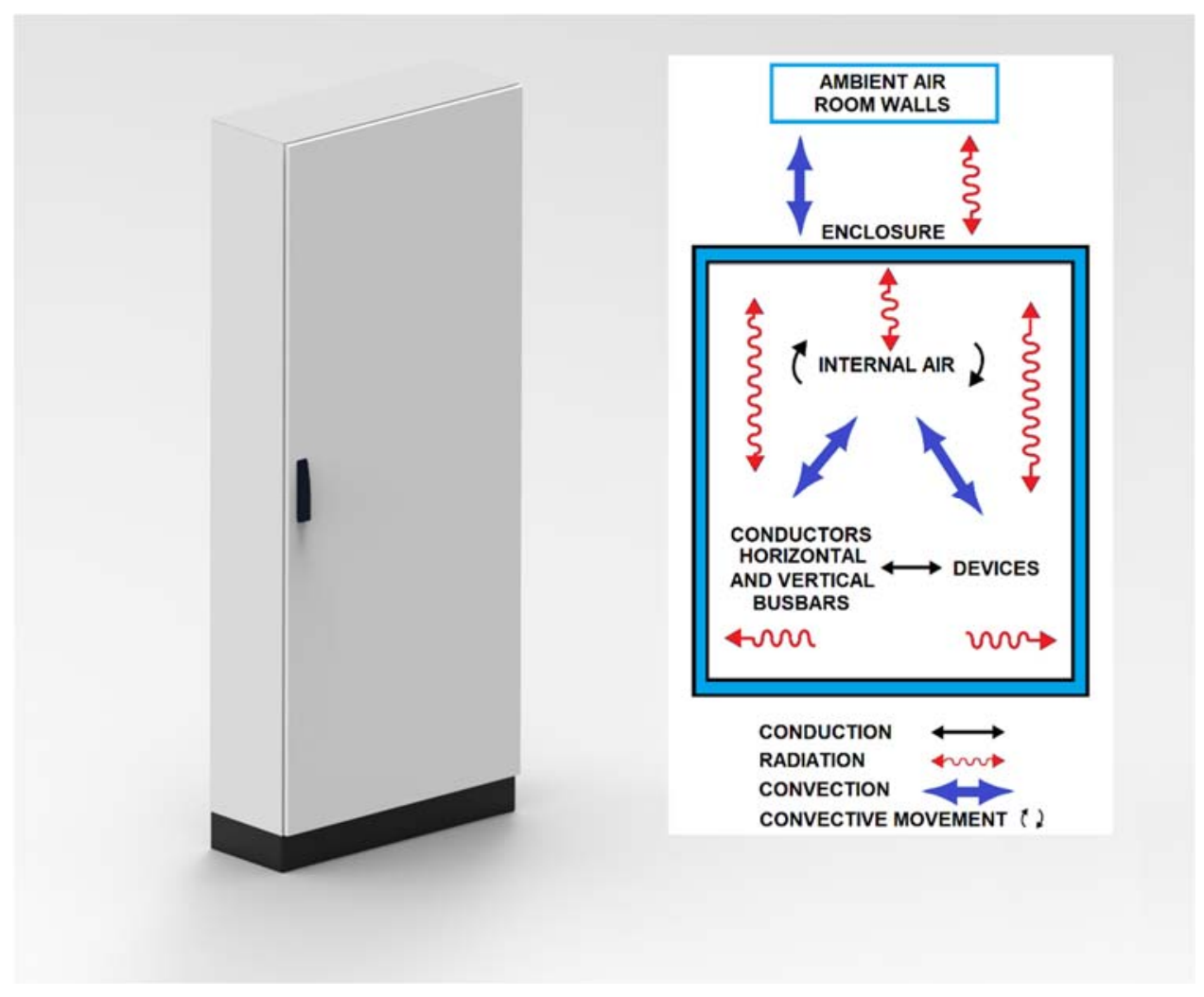

Figure 1. A scheme of heat dissipation in the switchgear by means of conduction, convection, and radiation.

The value of the electric power generated on a given busbar length is the aftermath of current and resistance, described below by means of the equation [38]:

$$
P=I^{2} x R
$$

where $P$ is the power dissipated per unit length $(\mathrm{W}), I$ is current in the conductor $(\mathrm{A})$, and $R$ is the resistance per unit length of the conductor $(\Omega)$. 
All calculations related to the current flow in the busbars and the distributions of the electromagnetic field in the switchgear are possible using the following Maxwell equations [39]:

$$
\begin{gathered}
\nabla x\{H\}=\{J\}+\left\{\frac{\partial D}{\partial t}\right\}=\left\{J_{s}\right\}+\left\{J_{e}\right\}+\left\{J_{v}\right\}+\left\{\frac{\partial D}{\partial t}\right\} \\
\nabla x\{E\}=-\left\{\frac{\partial B}{\partial t}\right\} \\
\nabla \times\{B\}=0 \\
\nabla \times\{D\}=\rho
\end{gathered}
$$

where $\nabla x$ is the curl operator, $\nabla$ is the divergence operator, $\{H\}$ is the magnetic field intensity vector, $\{J\}$ is the total current density vector, $\{J \mathrm{~J}\}$ is the applied source current density vector, $\{J e\}$ is the induced eddy current density vector, $\{J v\}$ is the velocity current density vector, $\{D\}$ is the electric flux density vector, $t$ is the time, $\{E\}$ is the electric field intensity vector, $\{B\}$ is the magnetic flux density vector, $\rho$ the electric charge density.

For the calculation concerning the coupled heat transfer process between the carrier fluid (air) and the solid domains, the Navier-Stokes equation is used alongside the energy equations, and those were described below [40]:

The continuity equation is given by:

$$
\frac{\partial u}{\partial x}+\frac{\partial v}{\partial y}+\frac{\partial w}{\partial z}=0
$$

and the momentum equation:

$$
\rho \vec{v} \cdot \vec{\nabla} \vec{v}=-\vec{\nabla} p+\mu \vec{\nabla}^{2} \vec{v}+\vec{F}
$$

The expression of the energy equation is as follows [40]:

$$
\rho c_{p}\left(\frac{\partial T u}{\partial x}+\frac{\partial T y}{\partial y}+\frac{\partial T w}{\partial z}\right)=\frac{\partial}{\partial x}\left(k_{t} \frac{\partial T}{\partial x}+u \tau\right)+\frac{\partial}{\partial y}\left(k_{t} \frac{\partial T}{\partial y}+v \tau\right)+\frac{\partial}{\partial z}\left(k_{t} \frac{\partial T}{\partial z}+w \tau\right)
$$

where $x, y, z$ are the Cartesian coordinates, $u, v, w$ are the velocities in $x, y, z$, directions, $\vec{v}$ is the velocity vector, $p$ is the pressure, $\rho$ is the density, $\mu$ is the dynamic viscosity, $\vec{F}$ is the body force vector, $T$ is the temperature, $k_{t}$ is the thermal conductivity of air, and $\tau$ is the viscous shear stress.

\subsection{Heat Dissipation by Convection in Busbar}

The amount of heat dissipated by convection depends on the shape, size of the rail, and the temperature increase around the rail [4]. Heat dissipation from the busbar by convection is different for horizontal and vertical surfaces, as shown in Figure 2 and the equation below $[38,39]$ :

$$
q_{c o n v}=W_{c} A_{c}=W_{v} A_{C v}+W_{h} A_{c h}
$$

where $W_{c}$ is heat dissipated per square meter due to convection $\left(\mathrm{W} / \mathrm{m}^{2}\right), \mathrm{A}_{\mathrm{c}}$ is the surface area of the conductor $\left(\mathrm{m}^{2}\right), W_{v}$ is heat dissipated per vertical square meter due to convection $\left(\mathrm{W} / \mathrm{m}^{2}\right), W_{h}$ is heat dissipated per horizontal square meter due to convection $\left(\mathrm{W} / \mathrm{m}^{2}\right), A_{\mathrm{Cv}}$ is the vertical surface area of the conductor $\left(\mathrm{m}^{2}\right), A_{c h}$ is the horizontal surface area of the conductor $\left(\mathrm{m}^{2}\right)$.

Convective heat exchange is influenced by: thermal conductivity coefficient, heat capacity, specific mass, kinematic viscosity, shape and dimensions of the cooled solid, and the nature of the cooling gas flow. In this paper, due to the lack of forced flow of the 
refrigerant, the issues concerning the forced convection are omitted. The thermal power transmitted to the environment by air convection is determined then by the formula $[38,39]$ :

$$
P_{k}=k_{k} S_{k}\left(T-T_{0}\right)
$$

where, $P_{k}$ is power transmitted by convection $(\mathrm{W}), \mathrm{k}_{\mathrm{k}}$ is the heat transfer coefficient by convection $\left(\mathrm{W} / \mathrm{m}^{2} \mathrm{~K}\right), \mathrm{S}_{\mathrm{k}}$ is heat dissipation surface $\left(\mathrm{m}^{2}\right), T$ is the temperature of the cooled element $(\mathrm{K})$, and $T_{0}$ is the ambient temperature $(\mathrm{K})$.

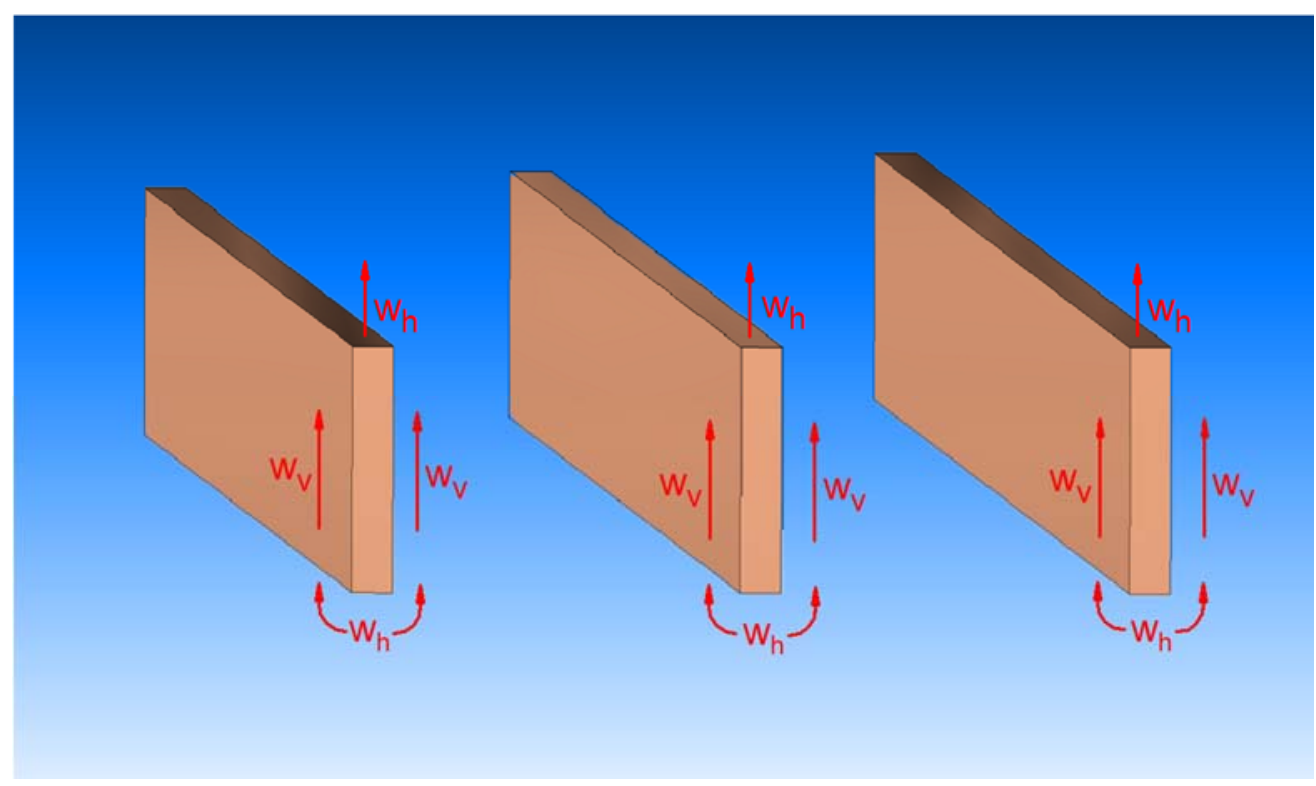

Figure 2. A scheme of heat dissipation in the switchgear.

Analytical determination of the amount of thermal energy transferred by convection is a difficult issue due to the large number of variables and the complexity of initial and boundary conditions. The coefficient values can be determined experimentally, with the proviso that the results obtained are valid only for the conditions occurring during the measurement. In the field of thermokinetics of electrical apparatuses, similarity theory is used to quantify the value of heat transfer that is causing hotter air to lift. Criterion numbers are described by the formulas below [38,39]:

$$
\begin{gathered}
N u=\frac{k_{k}}{\lambda} l_{w} \\
G r=\frac{g \beta \Delta T}{v_{r}^{2}} l_{w}^{3} \\
\operatorname{Pr}=\frac{v_{r}}{a_{t}} \\
R a=\frac{V_{\text {speed }}}{v_{r}} l_{w}
\end{gathered}
$$

where $\lambda$ is the thermal conductivity of the heat-carrying gas $(\mathrm{W} / \mathrm{mK}), l_{w}$ is the characteristic dimension of the body giving off heat (for cylindrical shapes, this will be the diameter, for flat bars arranged vertically-height) $(m), g$ is gravity constant $\left(9.8 \mathrm{~m} / \mathrm{s}^{2}\right), \beta$ is the coefficient of thermal expansion $(1 / K), v_{r}$ is the refrigerant lifting speed $\left(\mathrm{m}^{2} / \mathrm{s}\right), a_{t}$-temperature conductivity of the fliud $[\mathrm{W} / \mathrm{m} \cdot \mathrm{K}], V_{\text {speed }}$-cooling medium lifting spedd $[\mathrm{m} / \mathrm{s}]$.

For the case of cooling current paths through free airflow, the following dependency is used [38,39]:

$$
N u=f(G r \cdot P r)=c_{1}(G r \cdot P r)^{n_{1}}
$$


The values of the coefficients $c_{1}$ and $n_{1}$ depend on the result of the numbers $\mathrm{Gr}$ and $\mathrm{Pr}$, to which the respective shapes of current circuits can be assigned. Introducing the additional equation presented below allows the determination of the value of the coefficient $\mathrm{k}_{\mathrm{k}}[38,39]$ :

$$
\begin{gathered}
A=\frac{g \beta}{v_{r}^{2}} \operatorname{Pr} \\
k_{k}=\frac{\lambda \cdot c_{1} \cdot\left[A \cdot l_{w}^{3} \cdot\left(T-T_{0}\right)\right]^{n_{1}}}{l_{w}}
\end{gathered}
$$

Table 1 presents examples of coefficient values for frequently analyzed calculation cases of this type.

Table 1. The list of $c_{1}$ and $n_{1}$ values for a given Gr and Pr range.

\begin{tabular}{cccc}
\hline The Shape of the Cooled Element & Gr $\cdot$ Pr & $\boldsymbol{c}_{1}$ & $\boldsymbol{n}_{1}$ \\
\hline Switchboard vertical plate & $1.7 \times 10^{8}-2 \times 10^{10}$ & 0.15 & 0.33 \\
Horizontal plate (heat dissipation up top) & $2.3 \times 10^{8}-1.1 \times 10^{10}$ & 0.17 & 0.33 \\
Cylindrical busbar & $5 \times 10^{2}-2 \times 10^{7}$ & 0.54 & 0.25 \\
Rectangular busbar & $9.4 \times 10^{4}-4.6 \times 10^{6}$ & 0.60 & 0.25 \\
\hline
\end{tabular}

For busbars with simple shapes, the practical calculations of the heat transfer coefficient in the air, the simplified formulas below are often used [38,39]:

- For vertical planes, the following relation applies:

$$
k_{k}=7.66\left(\frac{\Delta T}{l_{w}}\right)^{0.25}
$$

- For horizontal planes:

$$
k_{k}=5.92\left(\frac{\Delta T}{l_{w}}\right)^{0.25}
$$

- For circular busbars:

$$
k_{k}=7.66\left(\frac{\Delta T}{l_{w}}\right)^{0.25}
$$

\subsection{Heat Dissipation by Radiation in Busbar}

The distribution of heat by radiation from the busbar to the environment is shown in Figure 3 and described in the following equation [38,39]:

$$
\begin{gathered}
q_{\text {rad }}=W_{R} A_{R}=5.70 \times 10^{-8} \times \mathrm{e}\left(T_{1}^{4}-T_{3}^{4}\right) \times A_{R} \\
\mathrm{e}=\frac{\varepsilon_{1} \varepsilon_{2}}{\left(\varepsilon_{1}+\varepsilon_{2}\right)-\left(\varepsilon_{1} \varepsilon_{2}\right)}
\end{gathered}
$$

where $W_{R}$ is heat dissipated per square meter due to radiation $\left(\mathrm{W} / \mathrm{m}^{2}\right), A_{R}$ is the surface area of the conductor $\left(\mathrm{m}^{2}\right), e$ is relative emissivity, $T_{1}$ is the average temperature of busbar $(K), T_{3}$ is the average temperature of the inner surface $(K), \varepsilon_{1}$ is the absolute emissivity of busbar, $\varepsilon_{2}$ is the absolute emissivity of the enclosure's inner surface.

For internal opposite surfaces of rectangular busbars, it is assumed that there is no radiation. The temperatures of these surfaces are approximately equal.

\subsection{Heat Absorption by Enclosure from Busbars}

When the short-circuit current flows through the busbars, a very large amount of heat is generated. It is transferred from busbars to the enclosure by means of radiation and convection. The rate at which the heat generated by the busbars is absorbed by the 
enclosure is proportional to the rate at which this heat is generated in the busbars by the flow of short-circuit current. This relation is described by the equation:

$$
P=q_{\text {conv }}+q_{\text {rad }}
$$

where $P$ is power dissipation per unit length of busbar $(W), q_{c o n v}$ is heat dissipation due to convection $(W), q_{\text {rad }}$ is heat dissipation due to radiation $(W)$.

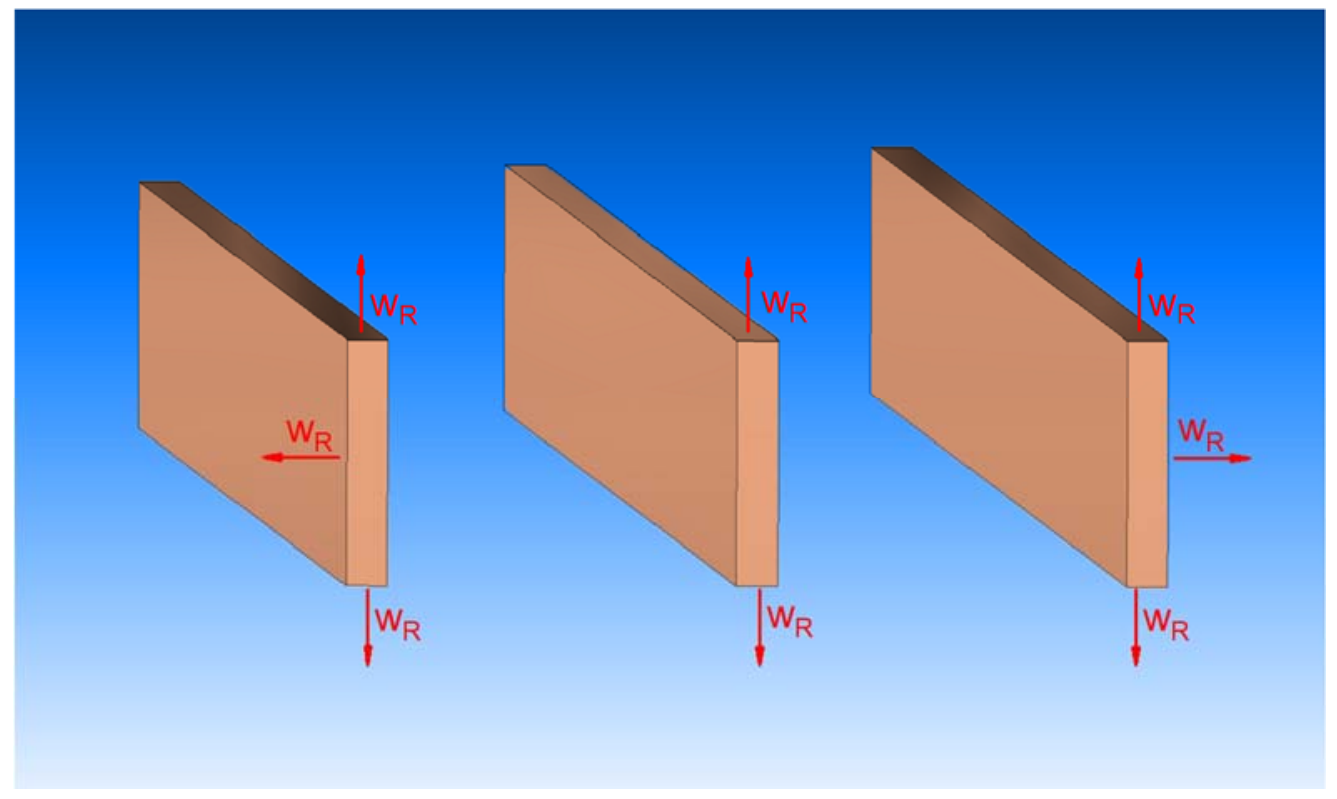

Figure 3. A scheme of heat dissipation from vertical busbars in the switchgear.

\subsubsection{Heat Absorption by Enclosure from Busbars by Convection}

The rate at which the heat dissipated by the busbars is absorbed to the enclosure via convection depends on the size, shape, and surface difference of the enclosure and busbars [5]. Heat absorbed by the enclosure via convection from busbars is different for vertical and horizontal surfaces of the copper busbars, as described in the equation [38,39]:

$$
q_{\text {conv }}=k_{\text {kvertical }} A_{v}+k_{\text {khorizontal }} A_{t}
$$

where $k_{\text {kvertical }}$ is average vertical convection heat transfer coefficient $\left(\mathrm{W} / \mathrm{m}^{2}\right), k_{\text {khorizontal }}$ is average top convection heat transfer coefficient $\left(\mathrm{W} / \mathrm{m}^{2}\right), A_{v}$ is the vertical surface area of enclosure $\left(\mathrm{m}^{2}\right)$, and $A_{t}$ is the top surface area of enclosure $\left(\mathrm{m}^{2}\right)$.

The heat absorbed via convection by the vertical plane can be calculated by means of equations [38,39]:

$$
\begin{gathered}
R a_{\text {vertical }}=\frac{g \beta\left(T_{1}-T_{3}\right) G_{1}^{3}}{v \cdot \alpha} \\
N u_{\text {vertical }}=0.22\left(\frac{P r}{0.2+P r} R a_{\text {vertical }}\right)^{0.28}\left(\frac{H}{G_{1}}\right)^{-1 / 4} \\
k_{k v 1}=\frac{N u_{\text {vertical }} k_{t}}{H}
\end{gathered}
$$

where $N u$ is average Nusselt number, $R a$ is Rayleigh number, $\beta$ is volumetric thermal expansion coefficient $\left(K^{-1}\right), g$ is gravity constant $\left(9.8 \mathrm{~m} / \mathrm{s}^{2}\right), T_{1}$ is the average temperature of busbar $(K), T_{3}$ is the average temperature of the inner surface $(K), H$ is the height of the enclosure $(m), G$ is the gap between the enclosure wall and busbar $(m), v$ is kinematic viscosity $\left(\mathrm{m}^{2} / \mathrm{s}\right), \alpha$ is thermal diffusivity $\left(\mathrm{m}^{2} / \mathrm{s}\right), k_{t}$ is thermal conductivity $(\mathrm{W} / \mathrm{mK})$, and $\mathrm{Pr}$ is the Prandtl number. 
The same applies to the heat absorbed by the horizontal plane by convection when heated from below, which can be calculated using the following equations [38,39]:

$$
\begin{gathered}
R a_{\text {horizontal }}=\frac{g \beta\left(T_{1}-T_{3}\right) G_{2}^{3}}{v \cdot \alpha} \\
N u_{\text {horizontal }}=0.0069 \mathrm{Ra}_{\text {horizontal }}^{1 / 3} \cdot \operatorname{Pr}^{0.074} \\
k_{k t 1}=\frac{N u_{\text {horizontal }} \cdot k_{t}}{H}
\end{gathered}
$$

\subsubsection{Heat Absorption by Enclosure from Busbars by Radiation}

The heat absorbed by the enclosure is equal to the dispersion of heat radiation from the busbars. This is described by the equation in point 2.2.

\subsection{Heat Transfer via Conduction through the Enclosure Wall}

Heat transfer through the sheets of the casing is carried out by means of conduction. This can be described in the following equations [38,39]:

$$
\begin{gathered}
P=q_{\text {cond }} \\
q_{\text {cond }}=k_{t} A \frac{\Delta T}{\Delta x} \\
\Delta=T_{3}-T_{4}
\end{gathered}
$$

where $P$ is power dissipation per unit length of busbar $(W), q_{\text {cond }}$ is heat conducted through enclosure rear sheet $(W), k_{t}$ is enclosure thermal conductivity $(W / m K), A$ is the surface area of enclosure $\left(\mathrm{m}^{2}\right), T_{3}$ is the average temperature of the outer enclosure surface $(K), T_{4}$ is the average temperature of the outer enclosure surface $(K)$, and $\Delta x$ is enclosure sheet thickness $(m)$.

\section{Three-Dimensional (3D) Model}

In order to perform computational simulations, it was necessary to prepare an accurate 3D model of the chosen switchgear. For this purpose, Solid Edge software was used, where all components of the switchgear were modeled. The created 3D model focused on the exact mapping of the arrangement and dimensions of all structural elements of the switchgear. The external dimensions of the switchgear were $800 \mathrm{~mm}$ (width), $1950 \mathrm{~mm}$ (height), and $300 \mathrm{~mm}$ (depth). The L1, L2, and L3 vertical busbars, i.e., the main supply bridge in the switchgear, connected the other horizontal busbars with the main switch. Fuse disconnectors were installed on the horizontal rail bridges. All copper busbars in the switchgear were $30 \times 10 \mathrm{~mm}$ in cross-section. On the horizontal rail bridges, metallic phase connections (jumpers) have been designed to withstand rated current flow in the switchgear busbars using short copper bars, also with a cross-section of $30 \times 10 \mathrm{~mm}$. In the prepared model, the requirement was to accurately reflect the busbar system, including insulators, brackets, and holders, because the results of simulations of current distribution, heat, and power losses are only then the closest to the results obtained in experimental conditions.

The prepared 3D model was modeled of many parts and assembled consisting of various shapes and different material parameters. Creating a very accurate 3D model of the switchgear was associated with a longer duration of calculations and more computational iterations. The main reason for the large number of calculations was the large number of surfaces, edges, and computational nodes in the generated mesh. The finished switchgear model was saved in the ". sat" format. This format is the most suitable for importing files in ANSYS.

In the simulations, the same detailed 3D model was used in the calculations with the Maxwell 3D and the Transient Thermal. The CFD solver used a 3D model cross-section that accurately reflected the location of the busbars and masking panels in the switchgear. 
Creating a "mesh" was an extremely important process during the discretization of the 3D model.

In Maxwell 3D analysis, the solver used the adaptive grid generator option, which automatically compacted the mesh during calculations until the assumed convergence parameter, "Energy error" of 1\%, was reached. The final amount of mesh elements for this solver was 379639. The Transient Thermal solver was made with a mesh of an appropriate density, which resulted in 513,304 mesh elements and 1,084,554 computational nodes.

In the CFD solver, due to the effects associated with boundary layers, e.g., between busbars and the surrounding air, the mesh was additionally condensed in these places. That made it possible to meet the requirements for the type of phenomenon simulated. Mesh size for CFD solver was 335,420 nodes and 331,140 elements, respectively.

The structural model of the switchgear is the most detailed 3D model. It contains all the details such as bolts, nuts, gaskets etc. Figure 4 shows different views of the structural model of the switchgear (prototype). The figure shows the open switchgear and the internal insert itself in the form of brackets, holders, and copper busbars, to which the main switchgear apparatuses were attached or connected with.

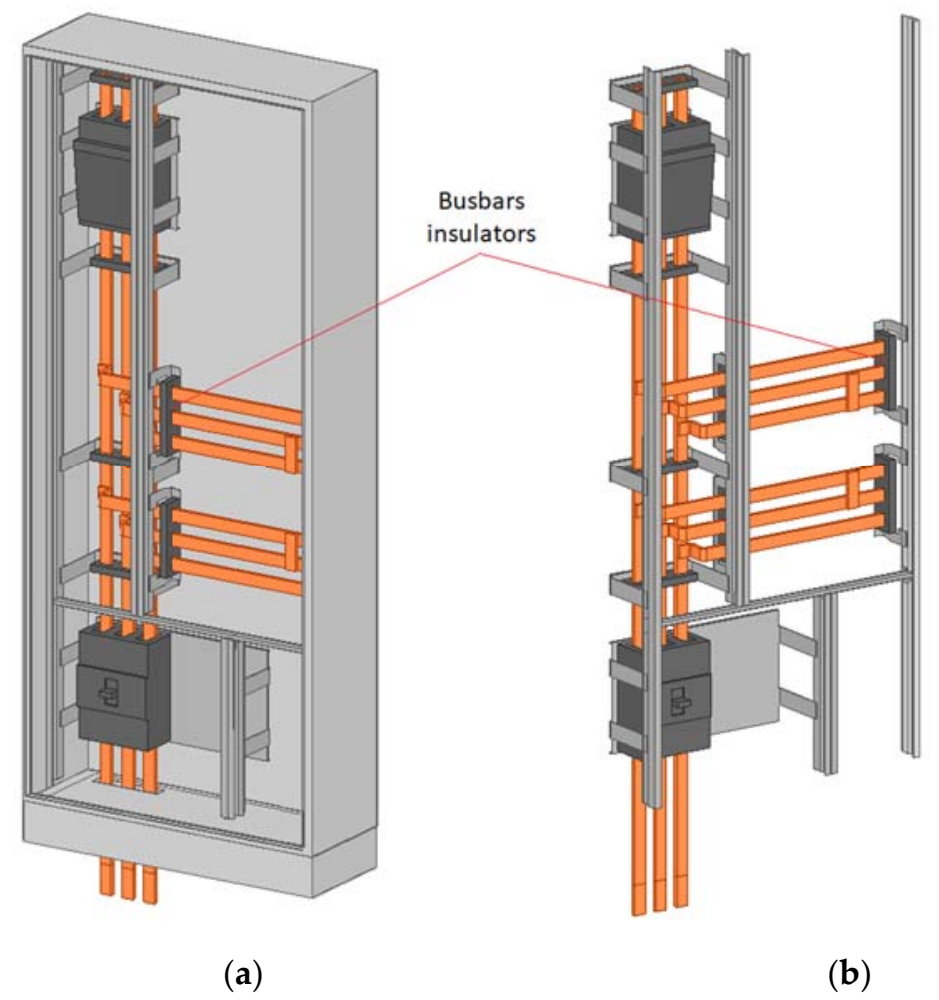

Figure 4. Views of the finished construction 3D model of the switchgear: (a) open; (b) the internal part of the switchgear.

\section{Coupled Electromagnetic, Transient Thermal and Fluid Flow Analysis (ANSYS Maxwell, Transient Thermal and Fluent CFD)}

\subsection{Simulation in Ansys Maxwell 3D—Rated Current Flow in Switchgear}

In order to conduct the analysis, it was necessary to implement the prepared 3D model of the switchgear. ANSYS Maxwell 3D software managed to load a previously prepared 3D model in ". sat" format. After importing the model, the solver type was chosen: "Eddy Current" and material properties for busbars, insulators, switchgear metal elements, housing as well as switchgear surroundings were given; in this case, it was air. All material properties were shown in Table 2. 
Table 2. Materials properties for electromagnetic and thermal analyses.

\begin{tabular}{|c|c|c|c|c|c|}
\hline Material & $\begin{array}{l}\text { Density } \\
\left(\mathrm{kg} / \mathrm{m}^{3}\right)\end{array}$ & $\begin{array}{l}\text { Specific Heat } \\
\left(\mathrm{J} / \mathrm{kg}^{*} \mathrm{~K}\right)\end{array}$ & $\begin{array}{c}\text { Thermal } \\
\text { Conductivity }\left(\mathrm{W} / \mathrm{m}^{*} \mathrm{~K}\right)\end{array}$ & $\begin{array}{c}\text { Electric } \\
\text { Conductivity }(\mathrm{S} / \mathrm{m})\end{array}$ & $\begin{array}{c}\text { Magnetic } \\
\text { Permeability }(\mathrm{H} / \mathrm{m})\end{array}$ \\
\hline Air & 1.205 & 1005 & 0.0257 & $3.00 \times 10^{-15}$ & $1.256 \times 10^{-6}$ \\
\hline Copper & 8960 & 385 & 401 & $5.81 \times 10^{7}$ & $1.256 \times 10^{-6}$ \\
\hline Structural Steel & 7850 & 434 & 60.5 & $6.21 \times 10^{6}$ & $1.256 \times 10^{-6}$ \\
\hline Galvanized Steel & 7833 & 481 & 52.0 & $5.88 \times 10^{6}$ & $1.256 \times 10^{-6}$ \\
\hline Polyethylene & 950 & 2300 & 0.28 & $6.3 \times 10^{-14}$ & $1.256 \times 10^{-6}$ \\
\hline
\end{tabular}

The values of rated currents were added to the main busbars supplying the switchgear. Busbars were entering the interior of the switchgear before the main switch. This is precisely reflected in the following Table 3 and Figure 5, where current excitation values for each phase of the L1, L2, and L3 switchgear current circuits were given and marked.

Table 3. Current excitations in 3-phase busbar in "Eddy Current" solution type.

\begin{tabular}{ccc}
\hline Phase of Busbar & Value (A) & Phase (deg) \\
\hline L1 & 630 & 0 \\
L2 & 630 & 120 \\
L3 & 630 & 240 \\
\hline
\end{tabular}

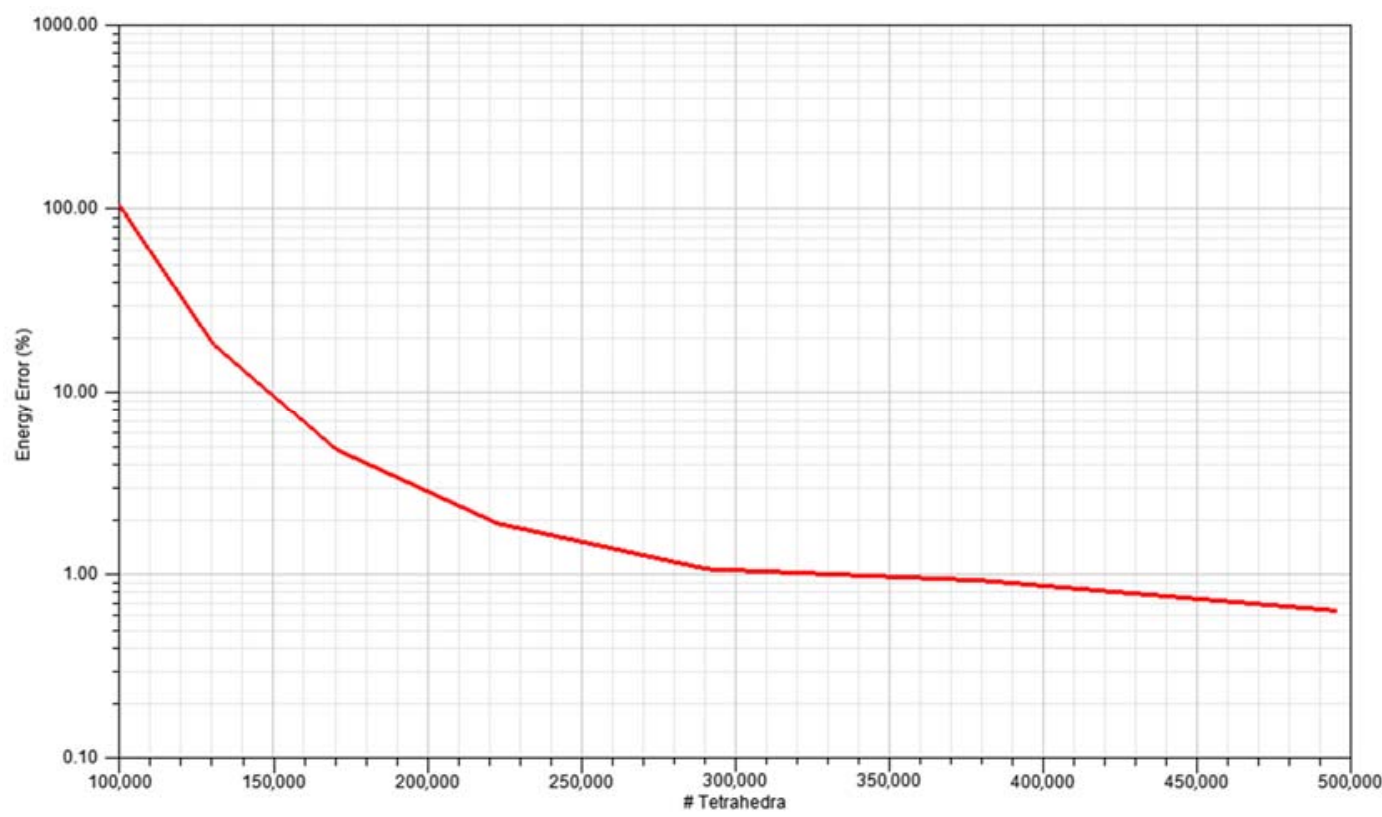

Figure 5. Convergence plot-energy error in relation to the number of "Tetrahedra".

After determining all boundary conditions for the simulation, it was possible to start the solver, which performed calculations for a three-phase rated current of $630 \mathrm{~A}$ in each of the busbar phases inside the switchgear.

Our calculations showed that the number of "Tetrahedra" components was equal to 379,639 elements with the assumed "Energy Error" below 1\%. Mesh density can be applied in the solver using an energy error estimation. The energy error is calculated by comparing the difference between the final averaged node value flux value for each node throughout the model. This error is then multiplied by the conductivity matrix for each node and integrated on each element to determine the energy error for that element. The energy error for the entire model is the sum of the energy errors for each element. Large energy error values mean that the flux field is very discontinuous, and small energy error values 
mean a more continuous flux field. While there are no absolute values for the energy error limits, a maximum percentage error of $1 \%$ is the recommended value [25]. To perform this analysis, the solver needed six computational iterations. Figure 5 illustrates the above amount of increased mesh elements with each subsequent calculation iteration.

Table 4 below shows the results of each iteration step for the number of Tetrahedra. Total Energy, Energy Error and Delta Energy elements. These are parameters which values determine whether the simulation results coincide. In the analyzed case, it can be seen that in the last six computational iterations, an "Energy Error" of $0.68203 \%$ was obtained, which is a satisfactory result.

Table 4. Number of iterations of calculation with the Energy Error accepted for calculation.

\begin{tabular}{ccccc}
\hline Pass & Tetrahedra & $\begin{array}{c}\text { Total Energy } \\
\mathbf{( J )}\end{array}$ & $\begin{array}{c}\text { Energy Error } \\
\mathbf{( \% )}\end{array}$ & $\begin{array}{c}\text { Delta Energy } \\
\mathbf{( \% )}\end{array}$ \\
\hline 1 & 100,267 & 429.44 & 104.34 & $\mathrm{~N} / \mathrm{A}$ \\
2 & 130,859 & 390.37 & 18.278 & 9.0977 \\
3 & 170,789 & 378.11 & 4.8174 & 3.1413 \\
4 & 222,883 & 373.48 & 1.9065 & 1.2243 \\
5 & 290,877 & 370.84 & 1.0733 & 0.70696 \\
6 & 379,639 & 369.51 & 0.68203 & 0.35688 \\
\hline
\end{tabular}

After using the post-processing function in ANSYS Maxwell 3D, the calculation results were generated in the form of drawings showing the current flow in the rails counting in Ohm losses or the distribution of electromagnetic induction in the body and metal parts of the housing. Ohm losses arising during the flow of currents through the busbars are expressed in $\left(\mathrm{W} / \mathrm{m}^{3}\right)$. In the metal housing and metal elements of the switchgear, under the influence of induced eddy currents, Ohm losses in the form of heat generated also arose. Figure 6 shows the exact distribution of Ohm's losses on a logarithmic scale in both busbars and metal components of the switchgear.

Another simulation result in the Maxwell 3D solver was the distribution of current density in current circuits expressed as $\left(\mathrm{A} / \mathrm{m}^{2}\right)$ and the distribution of the electromagnetic induction field expressed in Tesla. The highest value of current density was achieved in the sections of the busbars through which the rated currents flowed. In the case of electromagnetic induction field distribution, the highest values were generated in the bottom and rear sheet of the switchgear housing near the vertical rail bridge through which the rated currents for three phases flowed.

After analyzing the distribution of the electromagnetic induction field in each metal element, one can find the relationship between Ohm losses generated by eddy currents in the metal elements of the switchgear (bypassing copper bars). This relationship is extremely important because, in some cases, the local temperature may increase in the metal elements of the switchgear. It is caused by the induced eddy currents, which were not the desired phenomenon. The value of current density and electromagnetic induction field distribution was shown in Figure 7. 


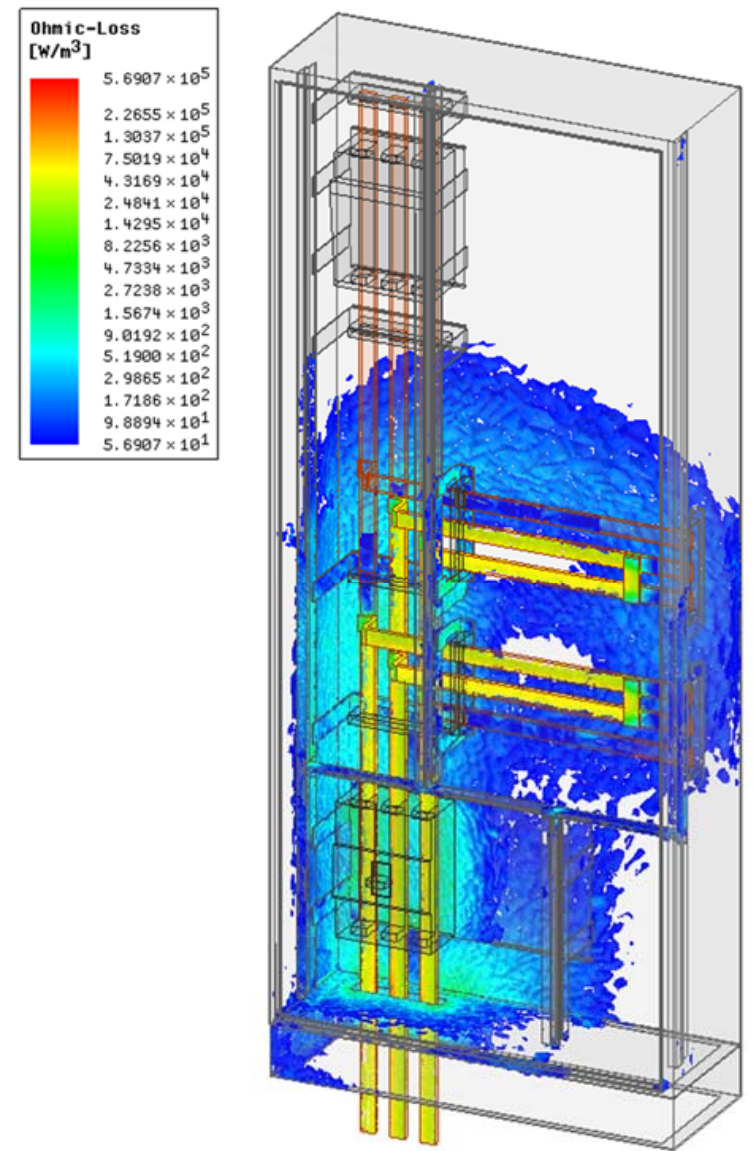

Figure 6. Ohm's loss distribution presented on a logarithmic scale in the switchgear.
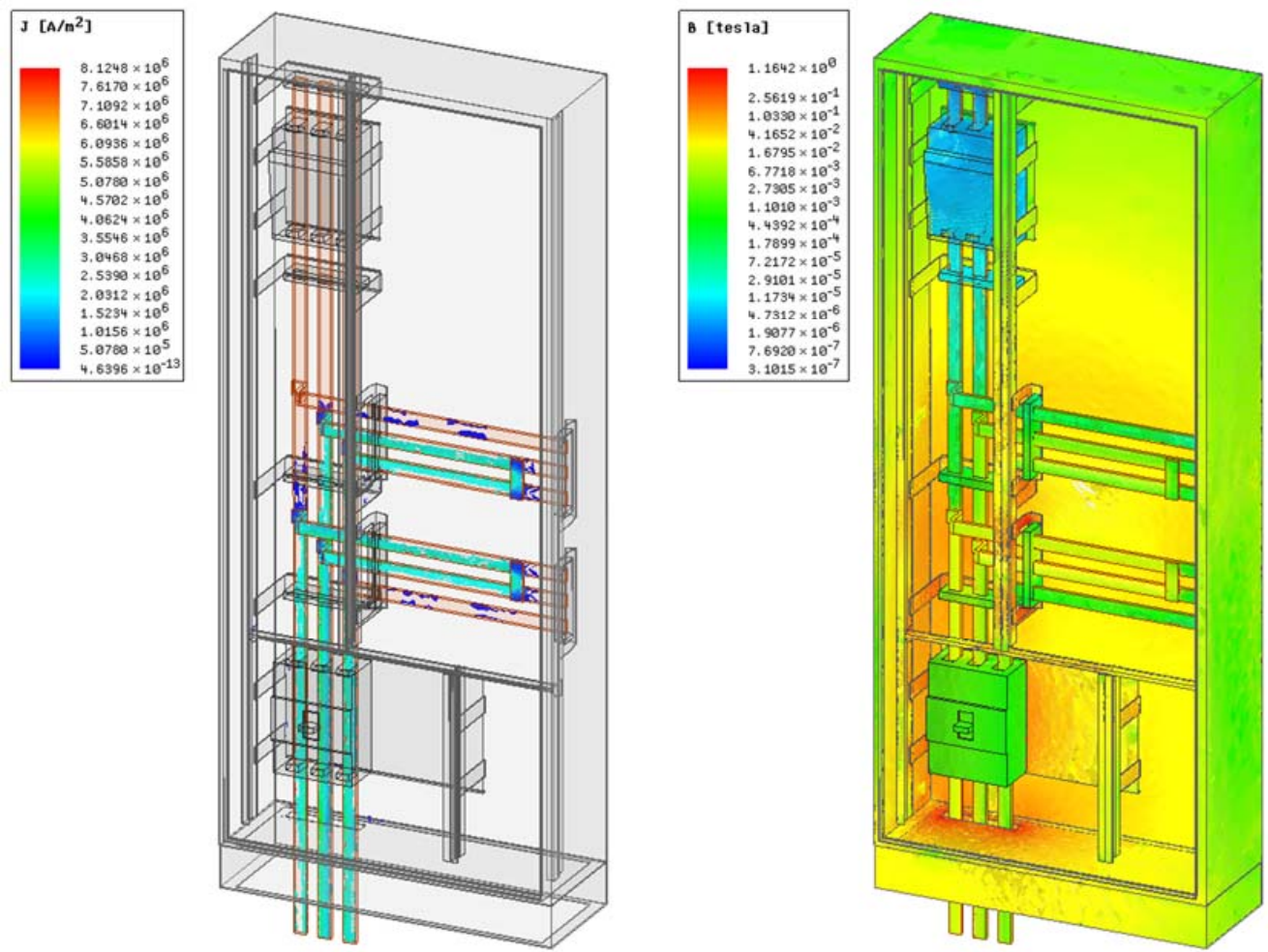

Figure 7. Current density distribution in busbars (on the left), electromagnetic induction field distribution in the switchgear (on the right). 


\subsection{Simulation in Transient Thermal-Heat Generation under the Influence of Rated Current Flow in the Switchgear Busbars}

After performing the computational operations related to the rated currents in Maxwell 3D, it was possible to start a coupled analysis consisting of the imported calculation results from the previous solver to the next calculation module, "Transient Thermal". To achieve this, the "Transient Thermal" solver was selected in the Workbench workspace and added to the "Maxwell 3D" solver, after which the two solvers were properly combined.

The next stage of the coupled analysis initiation was selecting the appropriate material data from the "Engineering Data" tab, which was used after opening the "Transient Thermal" solver to assign them to individual structural parts of the switchgear. Then the "mesh" was generated with the appropriate accuracy for this type of calculation.

After making a high-quality computational grid, the parameters for convection (film coefficient and ambient temperature) and radiation (emissivity and ambient temperature) for copper busbars were added to the solver. The ambient temperature of the switchgear was assumed as $22{ }^{\circ} \mathrm{C}$. It was possible to import the heat generation sources from the Maxwell 3D solver. To achieve this, the "Imported Load" option was used, the data were imported, and calculations were made.

At this stage, it was already possible to make calculations related to heat distribution in current circuits. The calculations were made for $7200 \mathrm{~s}$, which obtained the theoretical characteristics of the temperature values for the busbars placed in the housing, Figure 8. In addition, it was assumed that the insulators and switchgear construction withstood the resulting electrodynamic forces and mechanical stresses associated with them. It is known that in short-circuit conditions, it is not possible to achieve because, under the influence of electrodynamic forces and stresses, the switchgear structure could be disturbed, insulators could be destroyed, and rails could bend and melt after exceeding the Curie temperature.

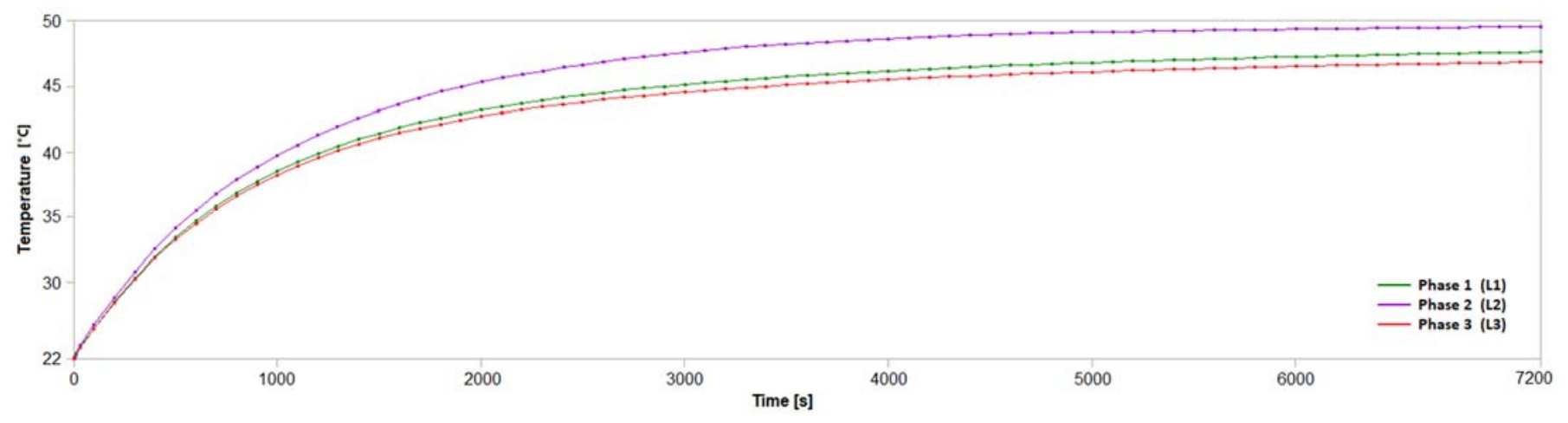

Figure 8. The characteristics of the theoretical establishment of the temperature value in the current busbars.

The characteristics obtained allowed for an assessment of when the maximum operating temperature of the current insulators used would be exceeded. In the analyzed case, the flame-retardant material used for insulators was a fireproof halogen-free polyester, which has a maximum operating temperature of $960^{\circ} \mathrm{C}$. The busbar temperature distribution for $7200 \mathrm{~s}$ was shown in Figure 9.

The above temperature distribution on the insulator ensures that the use of flameretardant material for support insulators for busbars allows to significantly extending the insulator's resistance to high temperature. At the same time, it increases the strength and reliability of the entire switchgear in the event of a short circuit, when a very high temperature can occur in the busbars during short-circuit conditions that are not the main objective of this work. 


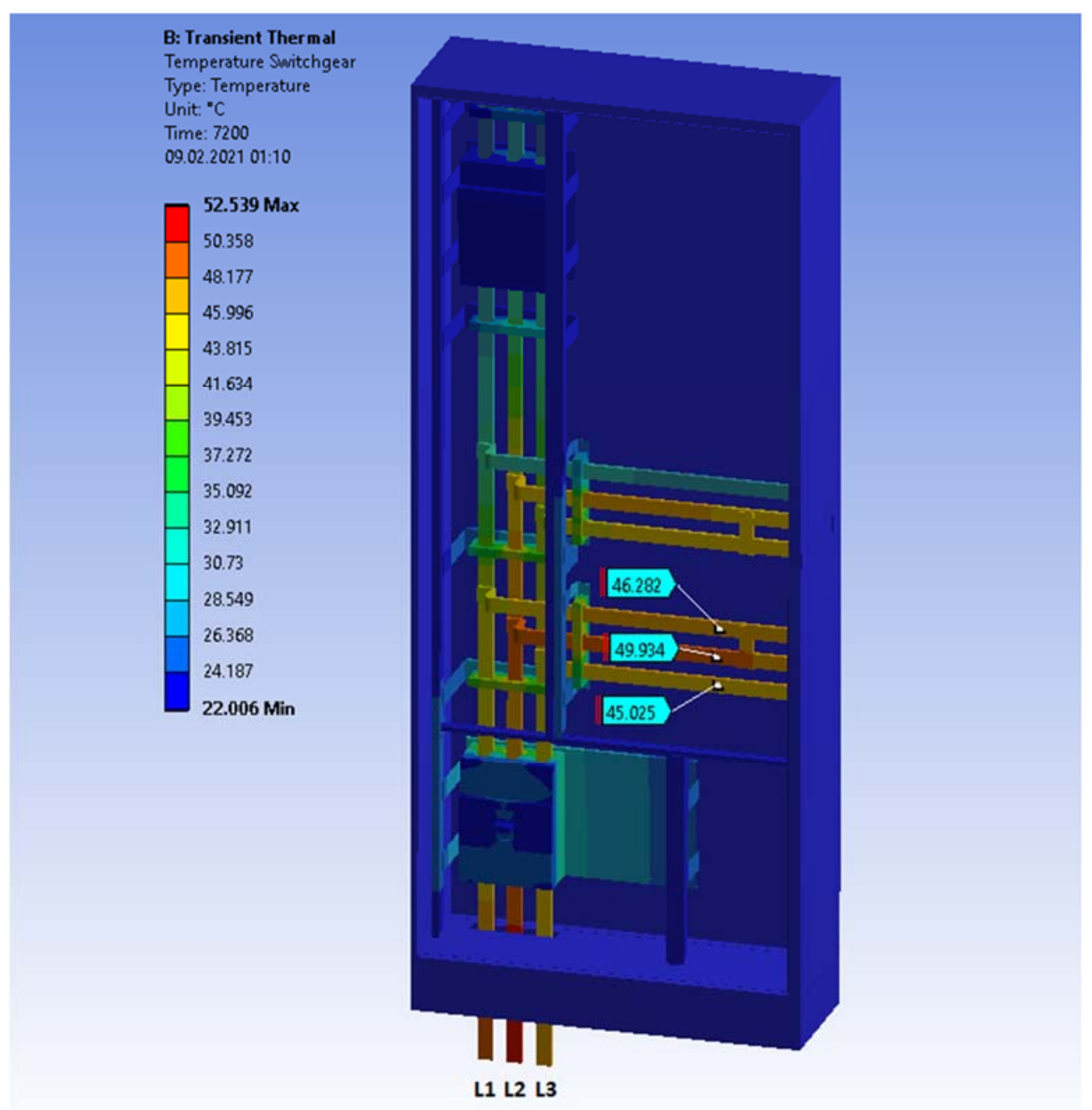

Figure 9. The temperature distribution in busbars and insulators during $7200 \mathrm{~s}$ simulation.

4.3. Simulation in ANSYS Fluent CFD-Heat Distribution from Busbars Inside the Enclosure under the Influence of Rated Current Flow in Switchgear Busbars

In order to investigate the impact of heat inside the low-voltage switchgear more widely at the operation at rated current conditions, another Fluent CFD (Computational Fluid Dynamic) solver was used. The CFD calculation module is originally used to simulate the flow of fluids, therefore obtaining results from it is an interpretation of the electromagnetic phenomena. The current carrying capacity of the busbars depends on the temperature discharge. Multiphysical simulations are now used to predict flow field and energy distribution. Using the 2D module, we can quickly orientate heat convection even from point sources (connections, mounting holes that reduce the conduction surface). This solver allows simulating the distribution of hot air through current rails using conduction, convection, and radiation inside the switchgear. This method is labor-intensive in preparation for calculations and requires large memory resources (high-end computer), such as a large random-access memory (RAM) and hard disk capacity, as well as a fast processor. This method allows you to perform the simulations for complex 3D models, thanks to which it is possible to analyze in detail the heat flow inside the developed and complicated construction of the low-voltage switchgear.

In order to use this method, it was necessary to properly prepare the geometric model of the switchgear model. An important task before making the calculations was the proper preparation of geometry and mesh, which in the CFD solver must be carefully refined. 
In the analyzed case, it was decided to use the Fluent CFD 2D solver, which required proper preparation of the $2 \mathrm{D}$ model of the modeled switchgear. For the purposes of simulation, a cross-section was made from the 3D structural model of the switchgear so as to obtain a preliminary 2D model of the switchgear. This process is thoroughly illustrated in Figure 10.

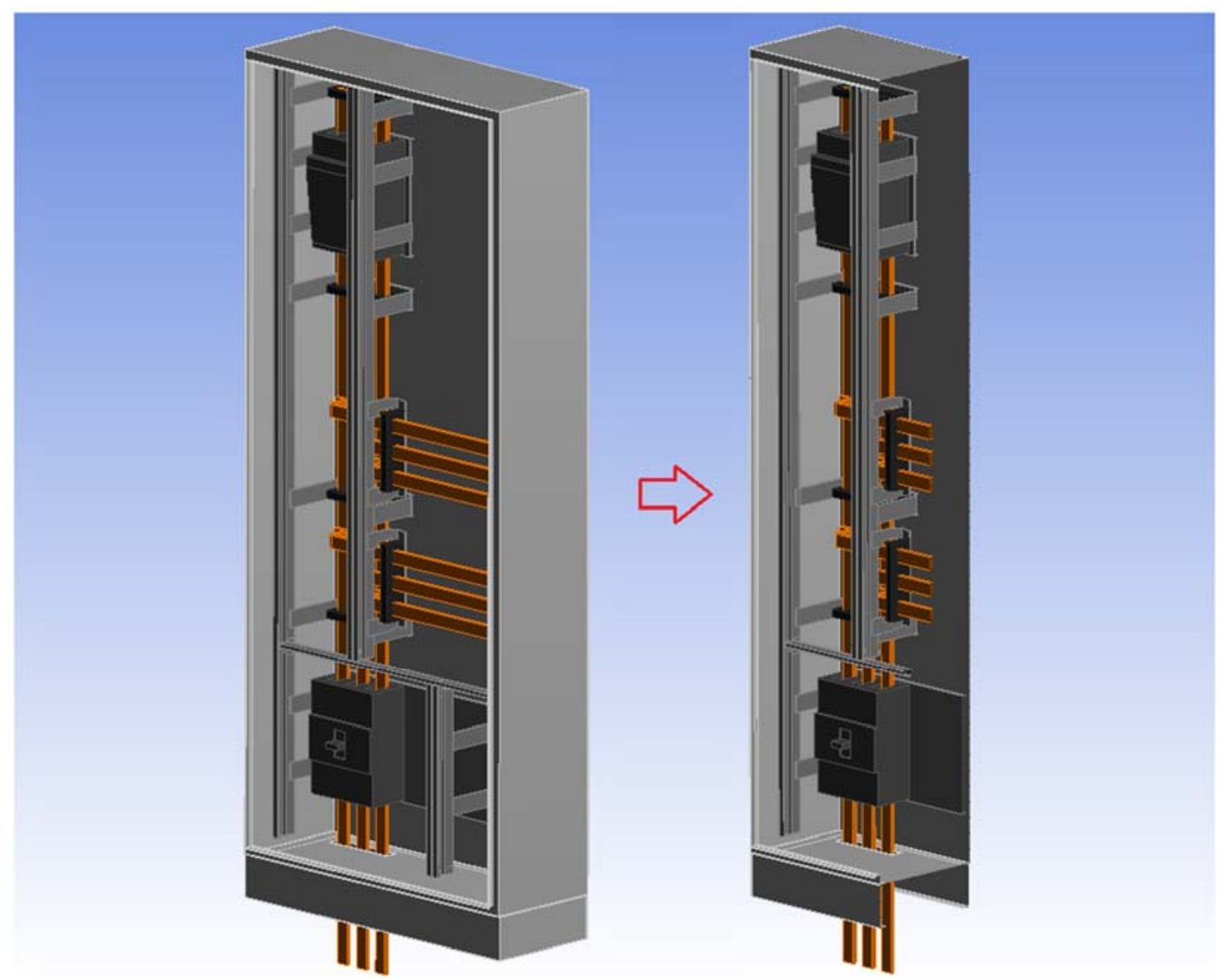

Figure 10. The switchgear cross-section necessary for calculations in Ansys Fluent 2D.

After importing the model into the solver, a mesh was prepared with properly concentrated places in the boundary layers, between the busbars, shields, and air. At this stage, all necessary parameters and conditions necessary to perform the simulation were set. Material properties have been defined for switchgear and air components. The same ambient temperature was used as for the simulation in Transient Thermal $\rightarrow 22^{\circ} \mathrm{C}$. Parameters have been defined in "Boundary Conditions" and "Cell Zone Conditions". Then, the simulation time steps were defined at the level of $1 \mathrm{~s}$ and the simulation length, which was assumed to be $7200 \mathrm{~s}$. After all the simulation settings, it was possible to start calculations in the Fluent CFD solver.

The simulation results are presented in Figure 11, where the convective distribution of heated air from current bars inside low-voltage switchgear is illustrated. The simulation results were presented for: $15,30,45,60,600,1800,3600$, and 7200 s of simulation time. The Fluent CFD solver needed 7200 computational iterations to perform a full simulation. 


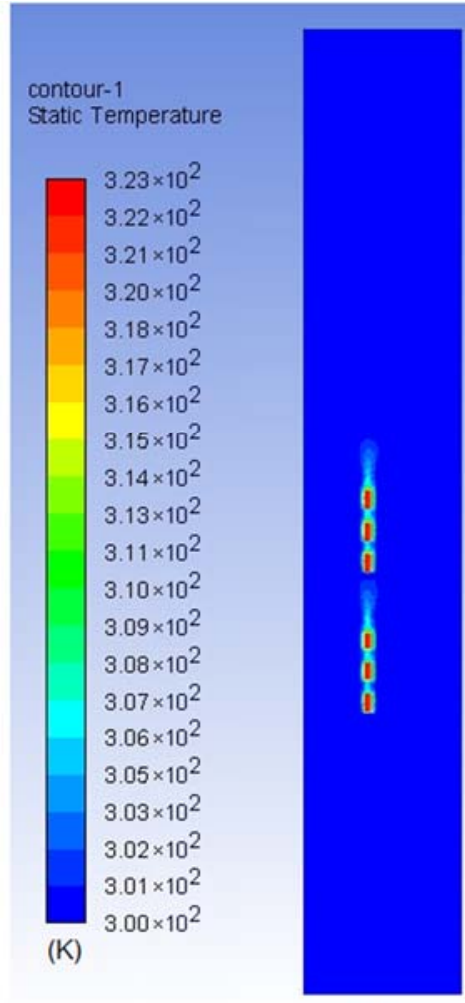

$15(\mathbf{s})$

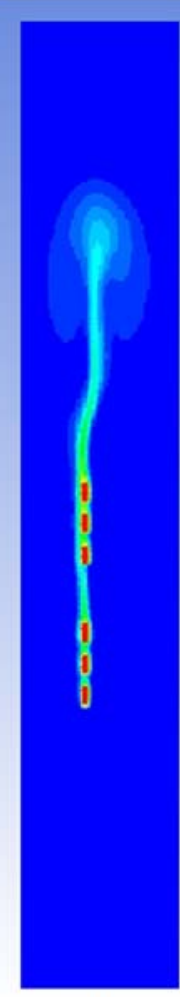

30 (s)

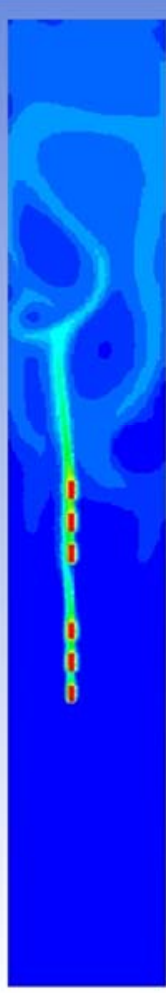

45 (s)

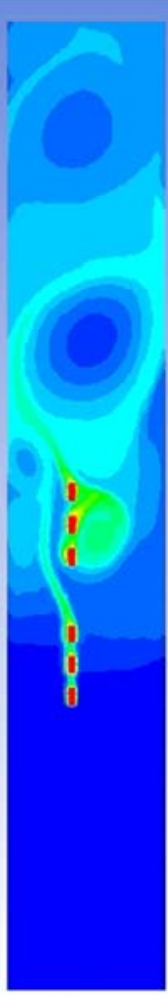

60 (s)

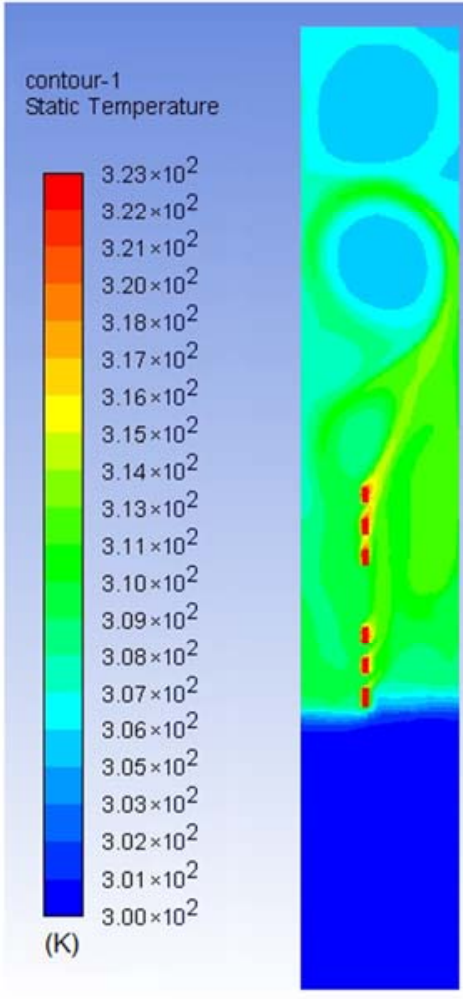

600 (s)

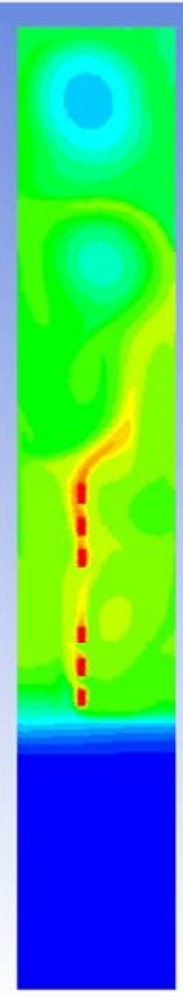

1800 (s)

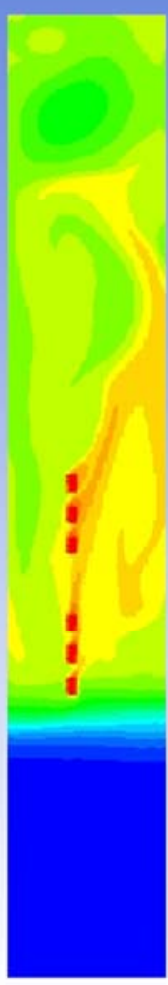

3600 (s)

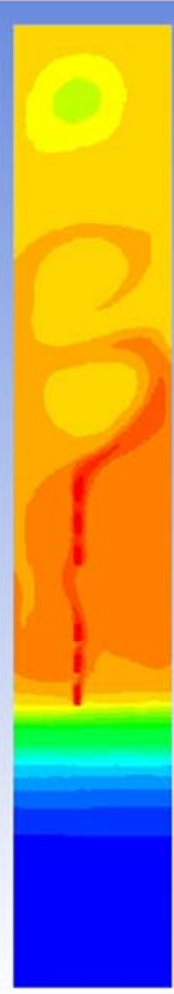

7200 (s)

Figure 11. The convective distribution of heated air inside the switchgear.

Further concluding the calculations in the Fluent CFD solver, it was possible to observe how the air heated intensively by the busbars behaves. In addition, the phenomenon of 
natural convection fueled the process of mixing cool and hot air inside the switchgear. As observed in the simulation results, the air temperature in the upper part of the interior of the switchgear that was up to $15 \mathrm{~s}$ of simulation duration would not threaten the wires and electrical apparatuses, while in the further part of the simulation, the temperature increased significantly. At these temperatures, the insulation of the wires and the housing of the switchgear melt. For $7200 \mathrm{~s}$, the temperature inside the switchgear exceeded $50{ }^{\circ} \mathrm{C}$, the temperature of this volume would not cause the inside of the switchgear to ignite.

\subsection{Additional Theoretical Short-Circuit Simulations}

Additionally, simulations in short-circuit conditions were procured in order to show thermal impact on the transmission elements of the switchgear (busbars, insulators). As it can be witnessed in Figures 12 and 13, the temperature during short circuits conditions, which involved the short-circuit current equal to $25 \mathrm{kA}$, exceeded $960^{\circ} \mathrm{C}$. Taking into account the temperature and electrodynamic forces influence the conditions may cause a fire in the switchgear, insulators fault, and even busbar destruction.

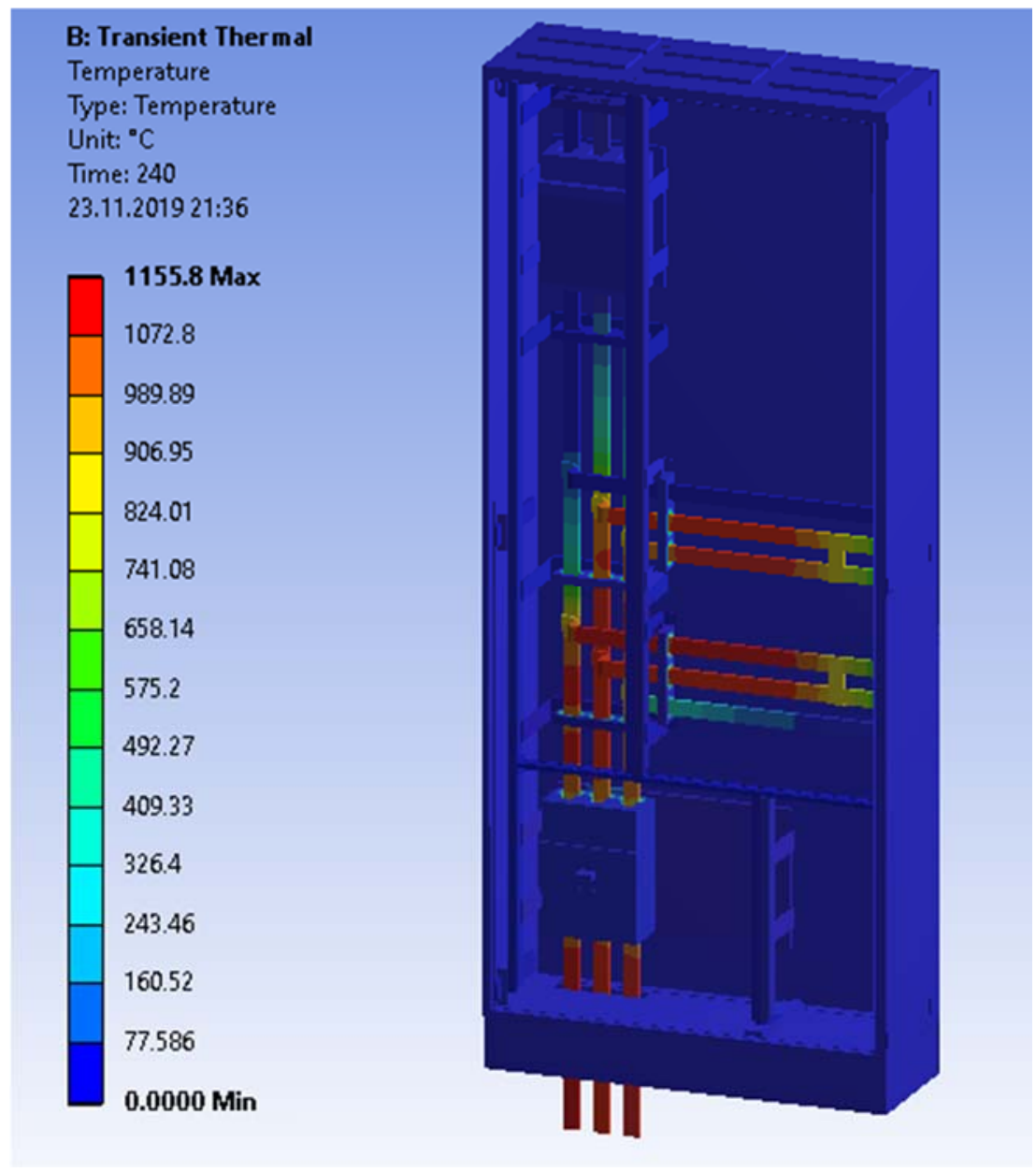

Figure 12. The convective distribution of heated air inside the switchgear in short-circuit conditions.

For short-circuit simulation, validation was not executed because of the very high costs of experimentation measures. Those simulations are theoretical and should be treated as additional content for this work. Those may be validated in future works. 

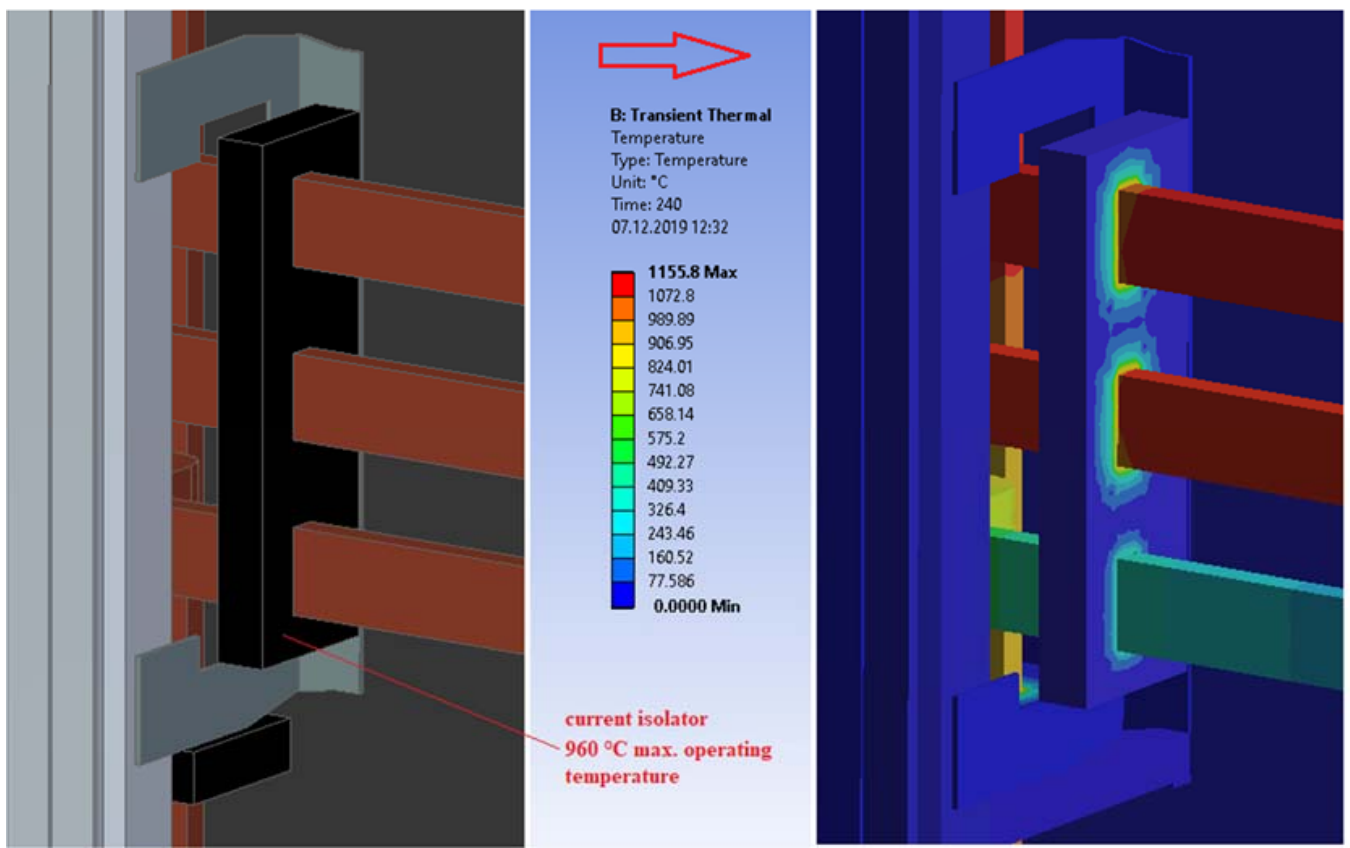

Figure 13. The temperature distribution in busbars and insulators during $240 \mathrm{~s}$ simulation in short-circuit conditions.

\section{Laboratory Setup}

5.1. Elements of the Test Stand

The laboratory layout was consisting of:

- The power supply device, i.e., a regulated mains current source and a three-phase transformer of these phase currents with values up to $1 \mathrm{kA}$ and output voltages adjustable with jumpers (Figure 14);

- $\quad$ Flexible cables of type LGY $2 \times 1 \times 150 \mathrm{~mm}^{2}$ connecting the above-mentioned transformer with switchgear busbars screw joints;

- Tested switchgear equipped with fuse switch disconnectors; thermocouples were glued to the switchgear temperature measuring points;

- Screen recorder with a 16-channel waveform measuring device, which, among other things, conducts the acquisition of measurements.

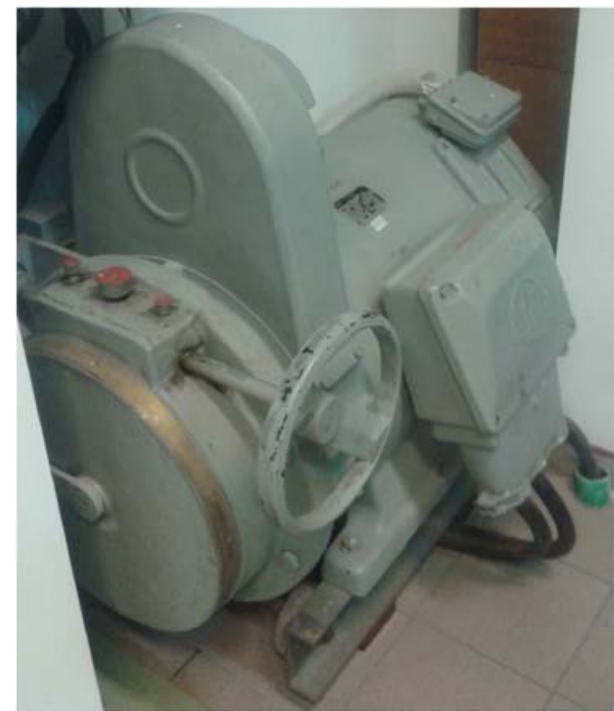

(a)

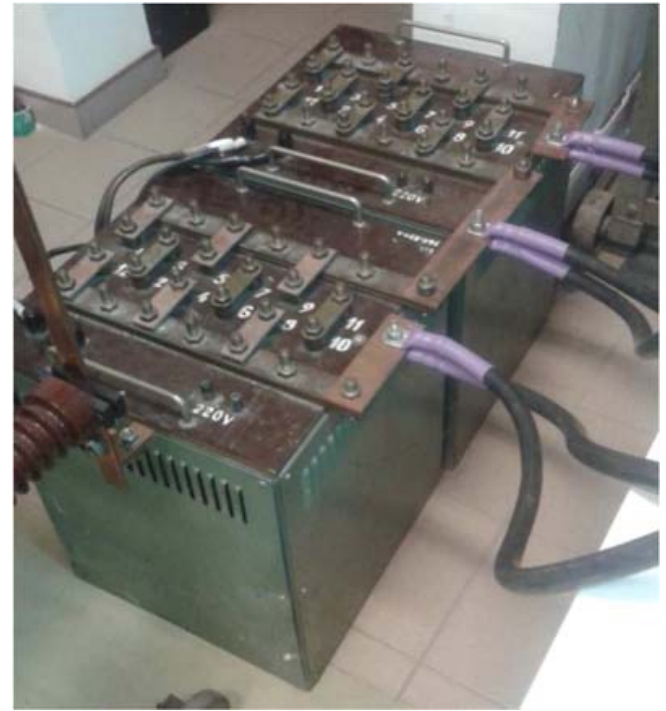

(b)

Figure 14. Power supply system used for tests: (a) three-phase regulated mains current source; (b) three-phase adjustable power transformer. 
The preparation of the measuring system in the laboratory was not complicated and relatively short, while the measurements took about $2 \mathrm{~h}$. The acquired practical knowledge makes it possible to state unequivocally that in order to obtain objective results, the stand should be expanded with additional measuring devices, for example, the possibility of measuring voltage drops on fuse-links and entire devices along with temperature increase. However, those were not obligatory for the means of results validation.

\subsection{Experimental Results}

Thermocouples were mounted in the contact space of the disconnectors being inside the switchgear-one for each apparatus. The results are graphically represented by curves. One of the thermocouples was placed in the upper part of the switchgear, above the tested disconnectors. The results of air temperature measurement in the switchgear are shown in Figure 15 below:

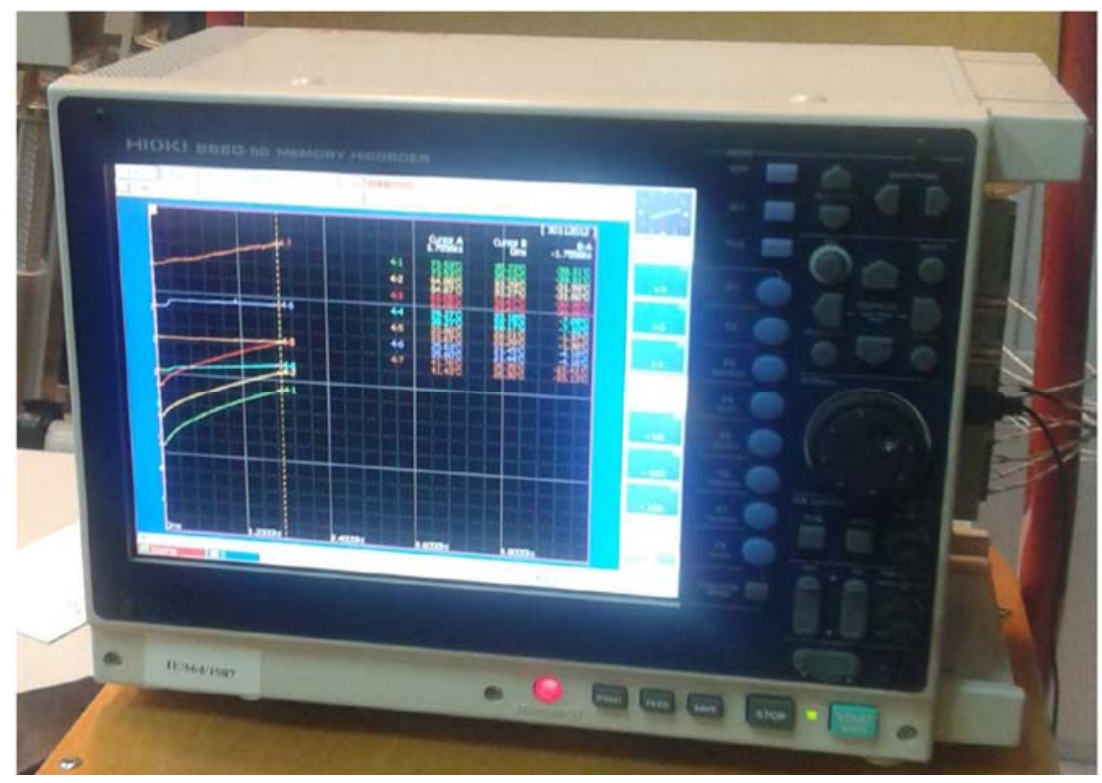

(a)

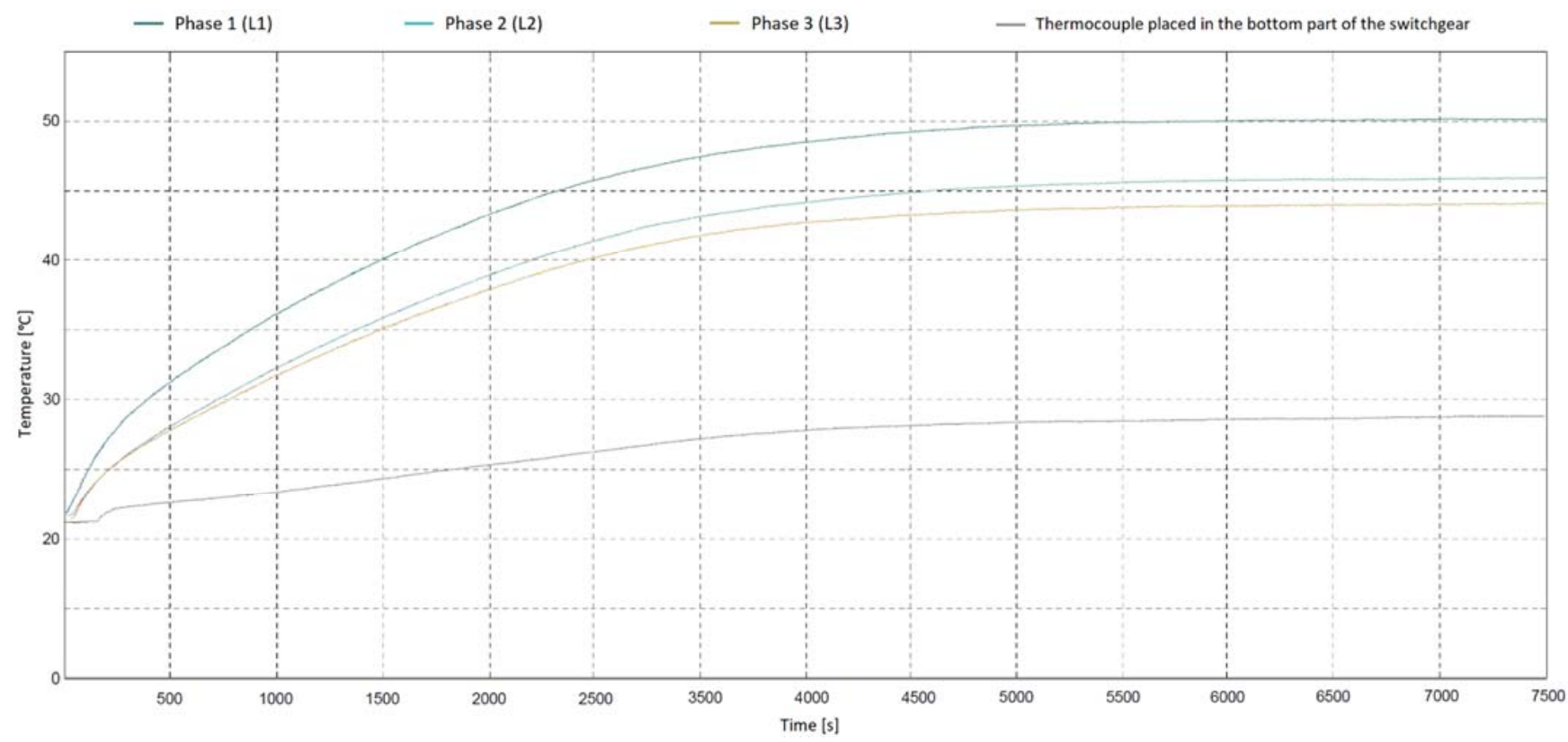

(b)

Figure 15. Experimental results: (a) measurement results; (b) measurement results for phase currents of approximately 630 A. 
Results values derived from simulations were significantly similar to those derived from experimental work. Therefore, those are validating positively 3D model functionality during rated current simulations.

\section{Conclusions}

The preparation of a detailed 3D model of low-voltage switchgear and the use of the coupled analyzes Maxwell 3D $\Leftrightarrow$ Transient Thermal $\Leftrightarrow$ Fluent CFD, is helpful and necessary when performing the thermal design of the low-voltage switchgears. It is essential in order to save time and resources during the design process. That mostly concerns the shape of busbars inside the switchgear and their placement, as it is essential for proper heat distribution.

The results of the Fluent CFD solver calculations are consistent with the calculations in the Transient Thermal solver and have been carried out correctly. The busbar temperature in both analyzes is confirmed and valid. The simulation in Fluent CFD provided additional information regarding heat distribution inside the switchgear associated with air convective movement models concerning conditions inside the switchgear.

The simulation results obtained proved that such simulations are an ideal tool for correctly designing the construction of low-voltage switchgear. This type of simulation verification of the prototype of the switchgear structure allows reducing potential construction errors and avoiding expensive experimental tests, which in the case of testing the heat flow inside the switchgear during a short circuit, are very complicated and require advanced equipment. Moreover, the simulation results were validated for rated conditions of employing currents equal to $630 \mathrm{~A}$. Validation for a value of $25 \mathrm{kA}$ was not possible due to the aspect of conducting very expensive research work. Nevertheless, the approximation is enough in order to evaluate FEM model functionality and accuracy.

The advantage of this analysis is that the creation of a 3D model of the switchgear and simulation are much faster than experimental research. Moreover, those are significantly reducing costs, which allows for rapid product development. The performed analyzes prove that this solution can be used in the case of complex projects involving the generation and distribution of heat inside switchgears.

These types of simulation solutions allow refining the design of low-voltage switchgears and obtaining more reliable construction solutions.

Author Contributions: Conceptualization, M.S., S.Ł., and Ł.K.; Data curation, M.S., S.Ł., and Ł.K.; Formal analysis, M.S., S.Ł., and Ł.K.; Investigation, M.S., S.Ł., and Ł.K.; Methodology, M.S., S.Ł., and Ł.K.; Project administration, M.S., S.Ł., and Ł.K.; Resources, M.S., S.Ł., and Ł.K.; Supervision, M.S., S.Ł., and Ł.K.; Validation, M.S., S.Ł., and Ł.K.; Visualization, M.S., S.Ł., and Ł.K.; Writing-original draft, M.S., S.Ł., and Ł.K.; Writing—review and editing, M.S., S.Ł., and Ł.K. All authors have read and agreed to the published version of the manuscript.

Funding: This research received no external funding.

Institutional Review Board Statement: Not applicable.

Informed Consent Statement: Not applicable.

Data Availability Statement: Not applicable.

Conflicts of Interest: The authors declare no conflict of interest.

\section{References}

1. Plesca, A. Thermal Analysis of Busbars from a High Current Power Supply System. Energies 2019, 12, 2288. [CrossRef]

2. Kim, M.; Bak, S.; Jung, W.; Hur, D.; Ko, D.; Kong, M. Improvement of Heat Dissipation Characteristics of Cu Bus-Bar in the Switchboards through Shape Modification and Surface Treatment. Energies 2019, 12, 146. [CrossRef]

3. Bedkowski, M.; Smolka, J.; Banasiak, K.; Bulinski, Z.; Nowak, A.J.; Tomanek, T.; Wajda, A. Coupled numerical modeling of power loss generation in busbar system of low-voltage switchgear. Int. J. Therm. Sci. 2014, 82, 122-129. [CrossRef]

4. Chapman, D.; Norris, T. Copper for Busbars; Copper Development Association Copper Alliance: Hertfordshire, UK, 2014. 
5. Barrett, R. Operating Temperature of Current Carrying Copper Busbar Conductors. Bachelor's Thesis, University of Southern Queensland, Toowoomba, Australia, 2013.

6. Lotiya, J. Thermal analysis and optimization of temperature rise in busbar joints configuration by FEM. In Proceedings of the 2014 6th IEEE Power India International Conference (PIICON), Delhi, India, 5-7 December 2014; pp. 1-5.

7. Smirnova, L.; Juntunen, R.; Murashko, K.; Musikka, T.; Pyrhönen, J. Thermal analysis of the laminated busbar system of a multilevel converter. IEEE Trans. Power Electron. 2016, 31, 1479-1488. [CrossRef]

8. Plesca, A.; Scintee, A. 3D thermal analysis of a power supply busbar structure. In Proceedings of the 2010 ASME 10th Biennial Conference on Engineering Systems Design and Analysis, Istanbul, Turkey, 12-14 July 2010; pp. 695-702. [CrossRef]

9. Barcikowski, F.; Lindmayer, M. Simulations of the heat balance in low-voltage switchgear. In Proceedings of the 20th Int. Conf. Elect. Contacts (ICEC 2000), Stockholm, Sweden, 19-23 June 2000.

10. Callegaro, A.D.; Guo, J.; Eull, M.; Danen, B.; Gibson, J.; Preindl, M.; Emadi, A. Bus bar design for high-power inverters. IEEE Trans. Power Electron. 2018, 33, 2354-2367. [CrossRef]

11. Wang, L.; Chiang, H.D. Toward online bus-bar splitting for increasing load margins to static stability limit. IEEE Trans. Power Syst. 2017, 32, 3715-3725. [CrossRef]

12. Geng, C.; He, F.; Zhang, J.; Hu, H. Partial stray inductance modeling and measuring of asymmetrical parallel branches on the bus-bar of electric vehicles. Energies 2017, 10, 1519. [CrossRef]

13. Kim, J.W.; Park, J.Y.; Sohn, J.M.; Ahn, K.Y. A study on thermal characteristics for D.C. molded cased circuit breaker busbar. Korean Inst. Electr. Eng. 2014, 11, 252-254.

14. Yaman, G. A thermal analysis for a switchgear system. J. BAUN Inst. Sci. Technol. 2019, 21, 72-80.

15. Yu, E.; Joshi, Y.K. Natural convection air cooling of electronic components in partially open compact horizontal enclosures. IEEE Trans. Compon. Packag. Technol. 2000, 23, 14-22. [CrossRef]

16. Delgado, F.; Renedo, C.J.; Ortiz, A.; Fernández, I.; Santisteban, A. 3D thermal modeland experimental validation of a low voltage three-phase busduct. Appl. Ther. Eng. 2017, 110, 1643-1652. [CrossRef]

17. Singh, S.; Summer, R. A novel approach for the thermal analysis of air insulated switchgear. In Proceedings of the 21st International Conference on Electricity Distribution, Frankfurt, Germany, 6-9 June 2011.

18. Bedkowski, M.; Smolka, J.; Bulinski, Z.; Ryfa, A.; Ligeza, M. Experimentally validated model of coupled thermal processes in a laboratory switchgear. IET Gener. Transm. Distrib. 2016, 10, 2699-2709. [CrossRef]

19. Guo, B.; Song, Z.; Fu, P.; Jiang, L.; Wang, M.; Dong, L. Prediction of Temperature Rise in Water-Cooling DC Busbar Through Coupled Force and Natural Convection Thermal-Fluid Analysis. IEEE Trans. Plasma Sci. 2016, 44, 3346-3352. [CrossRef]

20. Popa, I.C.; Dolan, A.I.; Ghindeanu, D.; Bolta su, C. Thermal modeling and experimental validation of an encapsulated busbars system. In Proceedings of the 2014 18th International Symposium on Electrical Apparatus and Technologies (SIELA), Bourgas, Bulgaria, 29-31 May 2014; pp. 1-4.

21. Muhammood, M.; Kamarol, M.; Ishak, D.; Masri, S. Temperature rise prediction in 3-phase busbar system at $20{ }^{\circ} \mathrm{C}$ ambient temperature. In Proceedings of the 2012 IEEE International Conference on Power and Energy (PECon), Kota Kinabalu, Malaysia, 2-5 December 2012; pp. 736-740.

22. Risdiyanto, A.; Arifin, M.; Khayam, U. Study on temperature distribution at busbar connection based on contact resistance of dierent plating contact surface. In Proceedings of the 2013 Joint International Conference on Rural Information Communication Technology and Electric-Vehicle Technology (rICT \& ICeV-T), Bandung, Indonesia, 26-28 November 2013; pp. 1-6.

23. Jung, H.S. Study for temperature rise on busbar of the switchgear and controlgear assemblies. Korea Inst. Inf. Commun. Eng. 2017, 21, 379-385.

24. Park, S.W.; Cho, H. A practical study on electrical contact resistance and temperature rise at at the connections of the copper busbars in switchgears. In Proceedings of the 2014 IEEE 60th Holm Conference on Electrical Contacts (Holm), New Orleans, LA, USA, 12-15 October 2014; pp. 1-7. [CrossRef]

25. Thompson, M.K.; Thompson, J.M. ANSYS Mechanical APDL for Finite Element Analysis; Butterworth-Heinemann: Oxford, UK, 2017; ISBN 978-0-12-812981-4.

26. Slade, P. Electrical Contacts: Principles and Applications; CRC Press: Boca Raton, FL, USA, 2014; ISBN 978-1-4398-8130-9.

27. Braunovic, M.; Myshkin, N.; Konchits, V. Electrical Contacts: Funamentals, Applications and Technology (Electrical and Computer Engineering); CRC Press: Boca Raton, FL, USA, 2006; ISBN 978-3642335723.

28. Braunovic, M. Characterization Techniques for Nanostructured Contact Materials. In Proceedings of the 56th IEEE Holm Conference on Electrical Contacts (HOLM 2010), Charleston, SC, USA, 4-7 October 2010. [CrossRef]

29. Szulborski, M.; Łapczyński, S.; Kolimas, Ł.; Kozarek, Ł.; Rasolomampionona, D.D. Calculations of Electrodynamic Forces in Three-Phase Asymmetric Busbar System with the Use of FEM. Energies 2020, 13, 5477. [CrossRef]

30. Łapczyński, S.; Szulborski, M.; Kolimas, Ł.; Kozarek, Ł.; Gołota, K. Mechanical and Electrical Simulations of Tulip Contact System. Energies 2020, 13, 5059. [CrossRef]

31. Kolimas, Ł.; Łapczyński, S.; Szulborski, M.; Świetlik, M. Low voltage modular circuit breakers: FEM employment for modeling of arc chambers. Bull. Pol. Acad. Sci. Tech. Sci. 2020, 68, 61-70.

32. Kühnel, C.; Schlegel, S.; Großmann, S. Investigations on the long-term behavior and switching function of fuse-elements for NH-fuse-links (gG) at higher thermal stress. In Proceedings of the 2017 6th International Youth Conference on Energy (IYCE), Budapest, Hungary, 21-24 June 2017. 
33. De Tommasi, L.; Magnani, A.; De Magistris, M. Advancements in the identification of passive RC networks for compact modeling of thermal effects in electronic device s and systems. Int. J. Numer. Model. Electron. Netw. Devices Fields 2018, 31, e2296. [CrossRef]

34. Kumar, A. Electro-thermal Characterizations, Compact Modeling and TCAD Based Device Simulations of Advanced SiGe:C BiCMOS HBTs and of nanometric CMOS FET. Ph.D. Thesis, Micro andnanotechnologies/Microelectronics, Université Bordeaux 1 Sciences et Technologie, Talence, France, 2012.

35. Di Napoli, F.; Magnani, A.; Copola, M.; Guerriero, P.; D'Alessandro, V.; Codecasa, L.; Tricoli, P.; Daliento, S. On-Line Junction Temperature Monitoring of Switching Devices with Dynamic Compact Thermal Models Extracted with Model Order Reduction. Energies 2017, 10, 189. [CrossRef]

36. Zhan, Y.; Kumar, S.V.; Sapatnekar, S.S. Thermal Aware Design. Found. Trends Electron. Des. Autom. 2007, 2, 255-370. [CrossRef]

37. VanGilder, J.; Tian, W.; Bean, J. Transient Thermal Analysis of an Air-Conditional IT Rack with a Thermal Buffering Unit. In Proceedings of the 19th IEEE Intersociety Conference on Thermal and Thermomechanical Phenomena in Electronics System (ITerm), IEEE, Orlando, FL, USA, 21-23 July 2020.

38. Ciok, Z. Switching Processes in Electric Power Systems; OWPW: Warsaw, Poland, 2001.

39. Frei, U.P.; Weichert, O.W. Simulation of electrical field and breakdown phenomena in low voltage circuits breakers. In Proceedings of the 23th Int. Conf. on Electrical Contacts, ICEC, Sendei, Japan, 6-9 June 2006; pp. 577-582.

40. Available online: https://www.ansys.com (accessed on 5 January 2021). 